\title{
Ribozyme Chemistry: to be or not to be under high pressure
}

\author{
Marie-Christine Maurel, ${ }^{*, \dagger}$ Fabrice Leclerc, ${ }^{\ddagger}$ and Guy Hervé \\ $\dagger$ †nstitut de Systématique, Evolution, Biodiversité (ISYEB), Sorbonne Université, CNRS, \\ Muséum National d'Histoire Naturelle, EPHE, F-75005, Paris, France \\ $\ddagger$ Institute for Integrative Biology of the Cell (I2BC), CNRS, CEA, Universite Paris Sud, \\ F-91198, Gif-sur-Yvette, France \\ ฯLaboratoire BIOSIPE, Sorbonne Université, Campus Pierre et Marie Curie, Institut de \\ Biologie Paris-Seine, CNRS, F-75005, Paris, France \\ E-mail: marie-christine.maurel@sorbonne-universite.fr
}

\begin{abstract}
The use of high hydrostatic pressure to investigate structure-function relationships in biomacromolecules in solution provides precise information about conformational changes and variations of the interactions between these macromolecules and the solvent, as well as the volume changes associated with their activity. The complementary use of osmotic pressure reveals quantitatively the extent and direction of the water exchanges between the macromolecules and the solvent and the number of water molecules involved in these exchanges. In this review, the chemistry of ribozymes and the influence of pressure is described. In the case of the hairpin ribozyme, pressure slowed down the self-cleavage reaction on the basis that the formation of the transition state involves a positive $\Delta V^{\neq}$of activation and the release of $78 \pm 4$ water molecules. The self-cleaving activity of the hammerhead ribozyme is also slowed down by pressure on the basis of kinetic parameters and $\Delta \mathrm{Vs}$ comparable to those of the hairpin ribozymes.
\end{abstract}


However, it appears that the solution of the hammerhead ribozyme used in this study contains two populations of molecules which differ by the values of these parameters. The results obtained in the case of small self-cleaving ribozymes containing adeninebulges are consistent with the hypothesis that these small RNAs that bind amino-acids or peptides could have appeared in prebiotic chemistry under extreme conditions in deep-sea vents or hydrothermal surface sites.

\section{Contents}

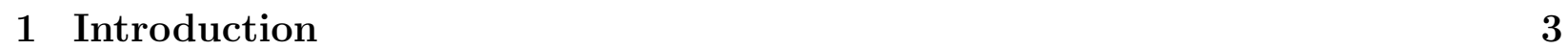



2.1 Self-cleaving small RNAs . . . . . . . . . . . . . . . . . . . 6

2.2 Viroids and the Hammerhead Ribozyme . . . . . . . . . . . . . . . . . . . . 8

$2.3 \quad$ RNA satellites of plant viruses and the hairpin ribozyme . . . . . . . . . . . 11

2.4 Varkud satellite ribozyme of Neurospora (VS) . . . . . . . . . . . . . . . . 14

2.5 RNA viruses and the HDV ribozyme . . . . . . . . . . . . . . . . . . . . 15

$2.6 \quad$ The riboswitch ribozyme glucosamine-6-phosphate (glmS ribozyme) . . . . . 16

2.7 The Ribosome . . . . . . . . . . . . . . . . . . . . . . . . 17



$3.1 \quad$ Pressure effects on cell physiology . . . . . . . . . . . . . . . . . . 18

3.2 Adaptations to high pressure . . . . . . . . . . . . . . . . . . . . 20

$3.3 \quad$ Pressure effects are based on volume changes . . . . . . . . . . . . . . . . . . 21

3.4 Electrostriction . . . . . . . . . . . . . . . . . . . . . . . 24

3.5 Influence of pressure on an equilibrium reaction . . . . . . . . . . . . . . 25

$3.6 \quad$ Influence of pressure on reactions catalyzed by enzymes . . . . . . . . . . . . 26

3.7 Osmotic Pressure $\ldots \ldots \ldots \ldots$. . . . . . . . . . . . . . . . . 26 


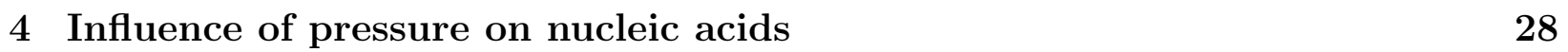

$4.1 \quad \mathrm{DNA} \ldots \ldots \ldots \ldots \ldots$

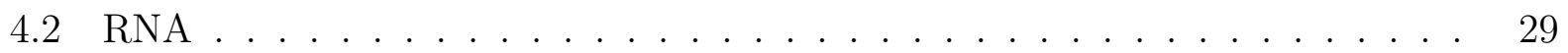

4.3 Loop-loop interactions, hairpins and bulges in RNA $\ldots \ldots \ldots$

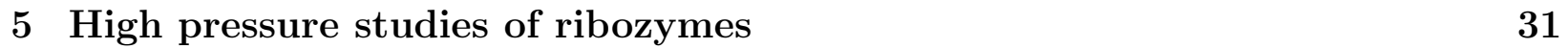

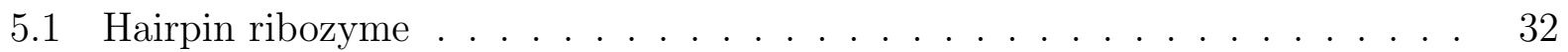

5.2 Hammerhead ribozyme $\ldots \ldots \ldots \ldots \ldots$

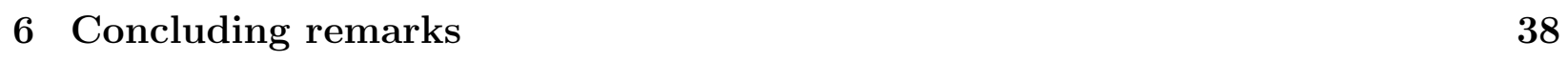

\begin{tabular}{lll}
\hline & Author Information & 41
\end{tabular}

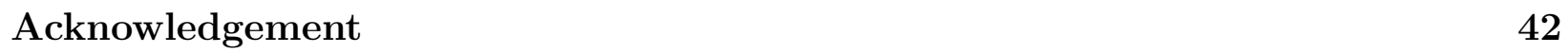

\begin{tabular}{ll}
\hline References & 42
\end{tabular}

\section{Introduction}

In 1983 Thomas Cech and Sidney Altman ${ }^{112}$ showed that certain classes of nucleic acids (ribozymes, a contraction of the terms ribo and enzyme) perform catalytic reactions. Although the catalytic capacities of the ribozymes initially seemed limited, ${ }^{3}$ the discovery of RNAs containing modified nucleotides and that of RNAs possessing various co-factors, ${ }^{4}$, 7 considerably enlarged the repertoire of reactions catalyzed by RNA. Furthermore, the use of the SELEX method allowed to devise new species of catalytic RNAs. $\frac{8}{7}$ These observations gave support to the RNA World hypothesis. ${ }^{9}$ This theory suggests that the present life form, based on DNA and proteins was preceded about four billion years ago by a simpler life form based exclusively on RNA. In such a world, the RNA molecule would have served as both the carrier of genetic information and as the catalyst for biochemical reactions. Capable of selfreplication, it could have ensured both the transmission and evolution of genetic material, 
and the control of the primeval metabolism. This hypothesis was first put forward in 1962 by Alex Rich, $\underline{10 \mid 11}$ then in 1967 by Carl Woese, $\frac{12}{12}$ and then developed in 1968, independently by Francis Crick, $\frac{13}{13}$ and Leslie Orgel. $\frac{14}{14}$ Then, in 1968 they presented the hypothesis whereby ribonucleic acids would have been the first molecules of the living world capable of stocking genetic information, of auto-replication and of performing catalytic reactions. $\underline{14}$

Although there is no direct evidence for the exact composition of the primitive atmosphere on Earth, $\frac{15}{15}$ the prebiotic environment is often associated with extreme conditions (redox, pH, temperature, pressure, etc) some of which are considered favorable for the prebiotic chemistry, such as the synthesis of building blocks of biomolecules. The necessary prebiotic conditions vary from one kind of biomolecule to another: eight different reaction conditions are reported under which their chemical synthesis might be optimal. 16 Alternatively, some of these building blocks may have been imported on Earth such as nucleobases which have been found in meteorites. ${ }^{17}$ On the other hand, the discovery of life forms in extreme environments on Earth is an argument to consider that life might have arisen in other planets with microorganisms tolerant or resistant to various conditions: thermophiles, acidophiles, alkaliphiles, xerophiles, halophiles, radioresistant, psychrophiles, and piezophiles. 18 Going further, one may also explore the presence of life elsewhere as our knowledge on planet systems and exoplanets and their atmosphere are expanding. ${ }^{192}$ From the chemical point of view, hydrothermal systems have been proposed as habitats for the first living organisms. These habitats provide some diverse and favorable conditions for the transition from the prebiotic chemistry to the early life metabolism. $\frac{23 \sqrt{25}}{2}$ From the evolutionary point of view, many thermophiles (or hyperthermophiles) were found in these habitats as closely related to the last universal common ancestor (LUCA). 26.28 However, the proposition to consider LUCA as a thermophile is controversial. $\stackrel{29}{32}$ Alternative views tend to consider that LUCA was rather a mesophile and that thermophiles just happen to colonize high-temperature environments later on. $\frac{33+36}{36}$ On the opposite, the cold temperature environments may have played a crucial role in the origin of life given that some psychrophiles can also tolerate high salt 
concentrations that make them halo-psychrophiles. ${ }^{37}$ Assuming that some prebiotic chemistry has emerged in separate conditions from the RNA world, a cold and radiation-shielded environment has been proposed for the origin of life before the emergence of a mesophilic LUCA. .38

For the same reasons, high-pressure conditions in deep regions of the Earth (e.g. ocean floor) are considered as a favorable habitat for the origin of life..$[39$ Various reactions of the prebiotic chemistry would be favored. $\frac{16 / 40}{16}$ The presence of a diversity of polyextremophilic microorganisms nowadays: from psychrophilic-piezophilic to mesophilic-piezophilic, and thermophilicpiezophilic in marine habitats $\frac{41}{41}$ and their metabolic capabilities ${ }^{42}$ have implications for the


conditions would have favored the formation of biopolymers. $\frac{43}{3}$ However, the RNA polymerization would require the pre-existence of nucleotides or activated nucleotides generated by nonenzymatic catalysis. $\stackrel{44}{4}$ Hydrothermal fields and alkaline hydrothermal vents are attractive ideas for sites that would be conducive to the origin of life. In similar conditions, short oligonucleotides can be synthetized under high pressure. ${ }^{45}$ Several studies have shown that the nucleotide synthesis is plausible under hydrothermal conditions. $\frac{46}{48}$ However, a direct experimental validation should be provided about the plausibility for these sites regarding the synthesis of nucleotides and oligonucleotides that are forbidden under alkaline conditions. ${ }^{49}$

If the modern ribozymes are the vestiges of the RNA World, $\underline{50,53}$ did they keep some features that are reminiscent of their ancient habitat? In the case of high pressure conditions, a few studies have been published on their effect on the catalytic activity of ribozymes but they are essentially focused on the hammerhead and hairpin ribozymes. Other self-cleaving ribozymes have been characterized and widely studied: their folding kinetics or catalytic mechanisms are sometimes similar and will be briefly discussed since they could provide some predictive value with respect to their possible behavior under high pressure. In order to understand the ribozymes and the effect of high pressure, an overview of the diversity of self-cleaving ribozymes and a description of the general effects of pressure at the molecular 
level will be provided. The more specific effects of pressure on the activity of ribozymes will finally be discussed.

\section{Different classes of ribozymes}

Twelve classes of natural ribozymes have been identified to date: the 9 classes from the family of small self-cleaving RNAs, ${ }^{54 \mid 55}$ the introns of groups $\mathrm{I}^{56}$ and II,, $57 / 58$ and ribonuclease P. .59

More recently, the ribosome and the spliceosome RNAs, were also identified as ribozymes. ${ }^{60 \mid 61}$

\subsection{Self-cleaving small RNAs}

Self-cleaving small RNAs contains ribozymes which are known for more than a decade: hammerhead, hairpin, glucosamine-6-phosphate riboswitch (glmS), ${ }^{6263}$ Hepatite Delta Virus (HDV) ${ }^{64}$ Varkud satellite (VS) from Neurospora ${ }^{65[66}$ and those discovered recently: twister and hatchet, ${ }^{67 / 68}$ pistol, 68169 and twister-sister. ${ }^{68}$ These ribozymes do not all share the same structural characteristics, but they have similar functions: they catalyze a specific and reversible trans-esterification which corresponds to their self-endonucleolytic cleavage. All the natural ribozymes catalyse an intramolecular single-turnover reaction ("in-cis" catalysis) as the catalyst is changed during the reaction.

This cleavage reaction is a transesterification of type SN2, inducing an inversion of the cleaved phosphate configuration (Figure 1). It begins with a nucleophilic attack of oxygen in 2' on the adjacent phosphorus, resulting in the formation of a bipyramidal trigonal transition state. The rupture of the 5' oxygen-phosphate bond generates the cleavage products corresponding to a 2'-3' cyclic phosphate end and a 5' free hydroxyl end. The two main chemical steps correspond to the nucleophilic attack and the departure of the leaving group. The ligation reaction is the exact reverse reaction, the oxygen in 5' being the nucleophilic group.

Detailed reaction mechanisms for these different ribozymes have been proposed in re- 


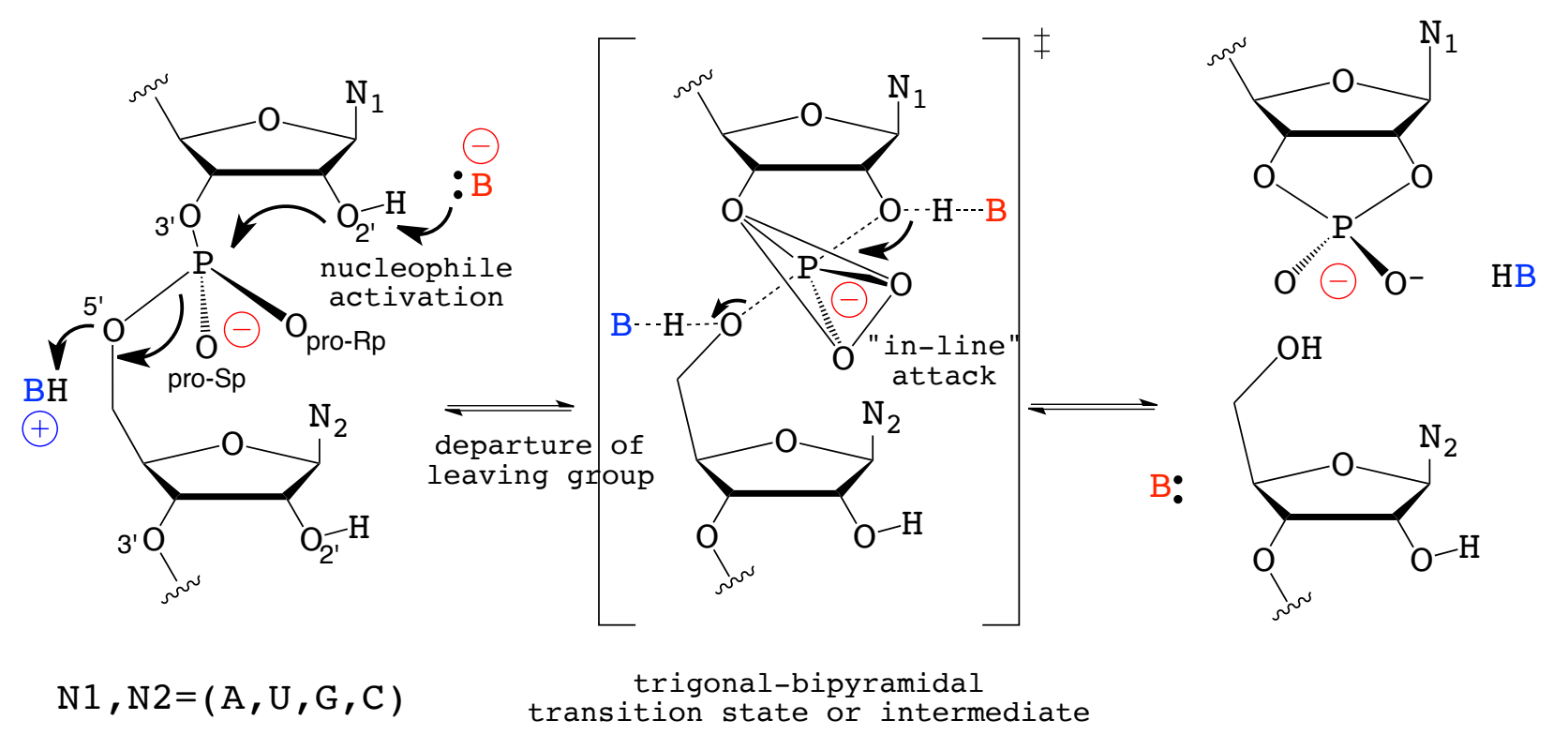

Figure 1: Reaction mechanism of ribozyme self-cleaving

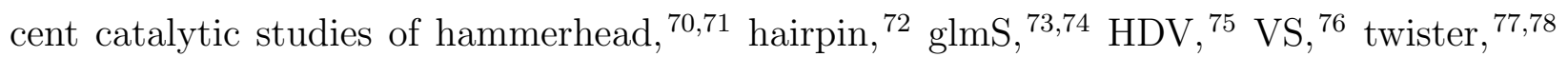
pistol, ${ }^{79}$ and twister-sister. ${ }^{80}$ Although the chemical reaction is the same in all self-cleaving ribozymes (Figure 1), the reaction mechanisms differ at the atomic scale due to the presence of specific catalysts and cofactors in the surroundings of the active site. For the sake of clarity, we make a distinction between catalysts and cofactors whether they are directly implicated in a chemical step or just facilitate the reaction. The self-cleaving ribozymes are not generally true metalloenzymes (Figure 22 ) since the catalysis does not involve any metal ion in the chemical steps except in the case of the HDV ribozyme (Figure 2b). However, the metal ions may act as cofactor to speed up the reaction and/or activate some catalyst ${ }^{81} 83$ as in the case of the hammerhead $\frac{70017184185}{2}$ or glmS ${ }^{173}$ ribozymes (Figure $2 \mathrm{~d}-\mathrm{e}-\mathrm{g}$ ). More often, they play a structural role in the folding of the active conformation prior to catalysis as in

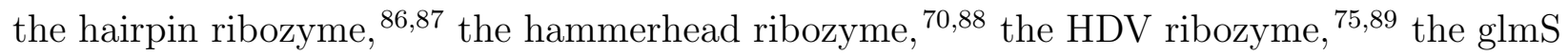
ribozyme, ${ }^{90}$ the VS ribozyme, ${ }^{91}$ the Twister ribozyme, ${ }^{92}$ the Pistol ribozyme, ${ }^{79}$ etc.

The catalysts involved in the chemical steps of the reaction can be as diverse as a protonated/deprotonated nucleobase, a metal ion, or a specific base for the activation of the nucleophile through the deprotonation of the $2^{\prime} \mathrm{OH}$ group ${ }^{54155193}$ (Figure 2). Similarly, a 
metal ion or a ionized nucleobase but also a ribose or a ligand can be used as catalysts in the departure of the leaving group (Figure 2). Many different cofactors may also contribute to the catalysis by stabilizing the negative charges on the phosphate groups before, during or after the formation of the trigonal-bipyramidal intermediate or transition state: neutral or ionized nucleobases, metal ions, ribose, etc. On the other hand, the kinetics of folding and formation of catalytically active conformations may require substantial changes in the active site that are dependent or independent from the microscopic changes in the active site (protonation/deprotonation, hydration/dehydration, ligand binding, etc) associated with the chemical steps of the reaction. Local changes in the active site and global changes at the global molecular level are often both required for an optimal catalysis, but it is not always clear which ones are the limiting processes.

Differences between the experimental reaction conditions (temperature, salts, pH, buffers etc.) of ribozymes have already shown that, like protein enzymes, catalytic RNAs are capable of exploiting several reaction mechanisms. QM studies also suggest that multiple competitive reaction pathways may coexist in the hairpin or hammerhead ribozymes. ${ }^{9495}$ Even when the catalyzed reaction is identical, each ribozyme adopts a unique structure and follows a distinct catalytic and kinetic mechanism. All these ribozymes undergo auto-cleavage at a unique specific site but use different catalytic strategies. The sequence of these natural ribozymes can be experimentally modified to obtain RNAs performing inter-molecular cleavages that consequently behave as true enzymes performing multiple turn-over reactions.

\subsection{Viroids and the Hammerhead Ribozyme}

Viroids are free naked infectious RNAs whose replication and propagation, unlike those of satellite RNAs, do not depend on the presence of a helper virus. There exist two families of viroids : Pospiviroidae and Avsunviroidae. The family of Avsunviroidae and some viral satellite RNAs contain a common structure of about 30 nucleotides known as "hammerhead ribozyme" whose secondary structure recalls that of the head of a hammer in the state 


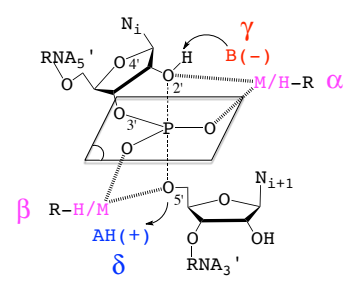

(a)

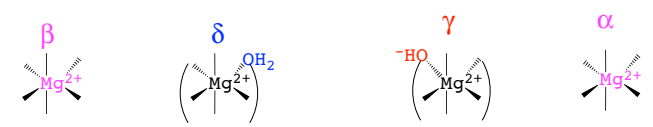

(b)



(c)
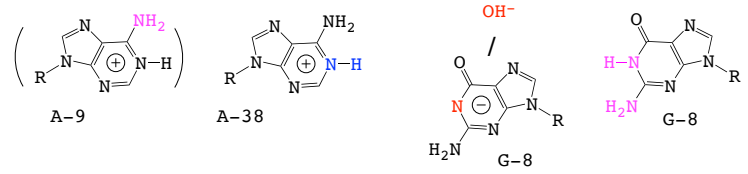

(d)
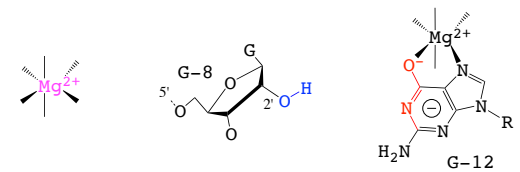

(e)
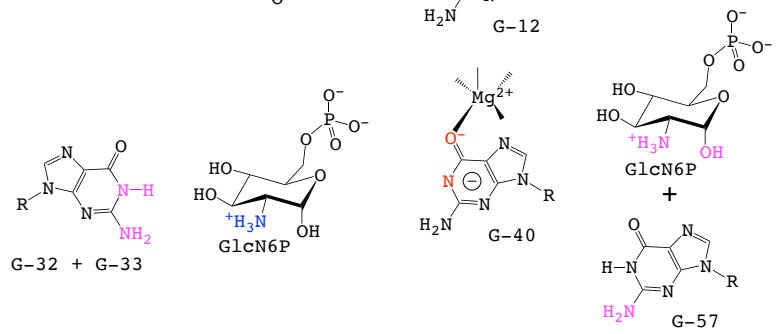

(f)


(g)


Figure 2: Catalysts and cofactors involved in self-cleaving ribozymes. (a) hypothetical metalloenzyme; (b) HDV ribozyme; (c) Hairpin ribozyme (the nucleophile activation may involve a deprotonated G nucleobase or alternatively a hydroxide ion); (d) Hammerhead ribozyme; (e) glmS ribozyme; (f) Neurospora Varkud Satellite (VS) ribozyme; (g) Twister (env22) ribozyme. Modified with permission from Leclerc, 2010. ${ }^{84}$ Copyright 2010 [MDPI] under [CC LICENSE]]. The activation of the nucleophile is achieved by the deprotonation of the 2'hydroxyl group (red); the departure of the leaving group is facilitated by the protonation of the 5'-oxygen (blue). $\gamma$ and $\delta$ correspond to the chemical steps usually associated with general or specific acid/base catalysis for the activation of the nucleophile and departure of the leaving group. $\alpha$ and $\beta$ correspond to residues or cofactors that facilitate the chemical steps by potentiating the nucleophile and the leaving group through the polarization and stabilization of the charges. 
where the catalytic core is still unfolded (state U); it corresponds to a three-way junction with single-stranded regions in the hammerhead core closed by three specific base-paired regions annotated stem I, II, and III that delineate the self-cleavage site of the ribozyme located between the stems I and III. In three dimensions, the hammerhead RNA folds into a Y-shape structure (state I and states F) where the stems II and III adopt a near-collinear stack configuration (Figure 3a).

The viroids share the same replication mode, called "symmetrical rolling circle" mechanism. .50 In this mechanism, the positive circular genomic RNA strand is transcribed by a polymerase from the host to give a linear oligomeric negative strand, which is cleaved at specific sites to generate linear negative monomers. Each of these monomers is circularized, then subjected to a second replication cycle in which it is transcribed several times to give a linear positive oligomer, which is then cut and re-circularized to produce new genomic RNAs. Catalytic units carried by such genomes are directly involved in the formation of replication intermediates: catalysing cut-off and ligation reactions, leading to the formation of linear monomers and their circularization during the replication process. These activities were demonstrated among plant viroids and virusoids that are circular satellite RNAs and linear satellite RNAs. It has been proposed that viroid RNAs are vestiges of an ancient RNA World. .96

As for many other ribozymes, the folding of the hammerhead ribozyme is dependent on the presence of divalent cations $\left(\mathrm{Mg}^{2+}\right)$. The folding kinetics follows a two-stage scheme from the unfolded state $(\mathrm{U})$ to some intermediate which is then converted to the folded state (Figure 3) as described in several studies. $\frac{9798}{9 n}$ In the minimal or truncated variants of the hammerhead ribozyme which were used in the first crystallographic studies, $\frac{99}{}$ the catalytic efficiency was sub-optimal. Some major conformational change was suggested in the following years although no structural evidence was provided initially. .00101 The $3 \mathrm{D}$ structure determination of the first natural and full-length hammerhead ribozymes confirmed the hypothesis of a conformational change that facilitates the formation of an active conformation $\frac{102}{10}$ and 
speeds up the catalysis. 103

The role of metal ion(s) as catalyst(s) has long been controversial in the case of the hammerhead ribozyme: being first considered in the 90's as a "metalloenzyme" with a single metal ion or two distinct metal ions as catalysts $\frac{104105}{10}$ and then as a false "metalloenzyme" just relying on nucleobases as catalyts as most of the other self-cleaving ribozymes. $\frac{106}{} \mathrm{Al}-$ though the metal ions do not seem to act as catalysts not being involved in the chemical steps of the reaction, they seem to be implicated as cofactors (Figure 2(d)). $\frac{70 \mid 71 / 85}{7}$

\subsection{RNA satellites of plant viruses and the hairpin ribozyme}

Hairpin ribozyme was found on the negative strand of satellite RNA of the tobacco ringspot virus. 109 111 It has since also been found on the negative strands of the satellites of the arabette mosaic virus and chicory spot virus. It catalyses both cleavage and ligation reactions, and therefore appears to be responsible for both the cleavage of linear multimers and the circularization of the resulting monomers during the viral replication cycle in vivo. In many of the RNA satellites of plant viruses, the hairpin ribozyme performs a reversible self-cleavage reaction involved in the maturation of the viral replication products.

In the tobacco ringspot nepovirus satellite RNA, the hairpin ribozyme folds into an extended cruciform structure corresponding to a 4-way junction with 4 stems annotated

from A to D. $112[113$ However, a truncated form with a L-shape keeps the catalytic activity in vitro with only the two arms of the 4-way junction corresponding to the stems $\mathrm{A}$ and B and their respective associated internal loops A and B. This "truncated" or "minimal" hairpin ribozyme with an L-shape is composed of two stem regions linked to one another, each containing an internal loop (Figure 4).

When these two domains come side by side $\left(D_{L}\right.$ state: docked and ligated), they promote tertiary interactions forming the active structure where the two domains are docked on each other (Figure 4). After self-cleavage, an intermediate with the docked conformation $\left(D_{C}\right.$ state: docked and cleaved) is formed before undocking and dissociation of the product with 


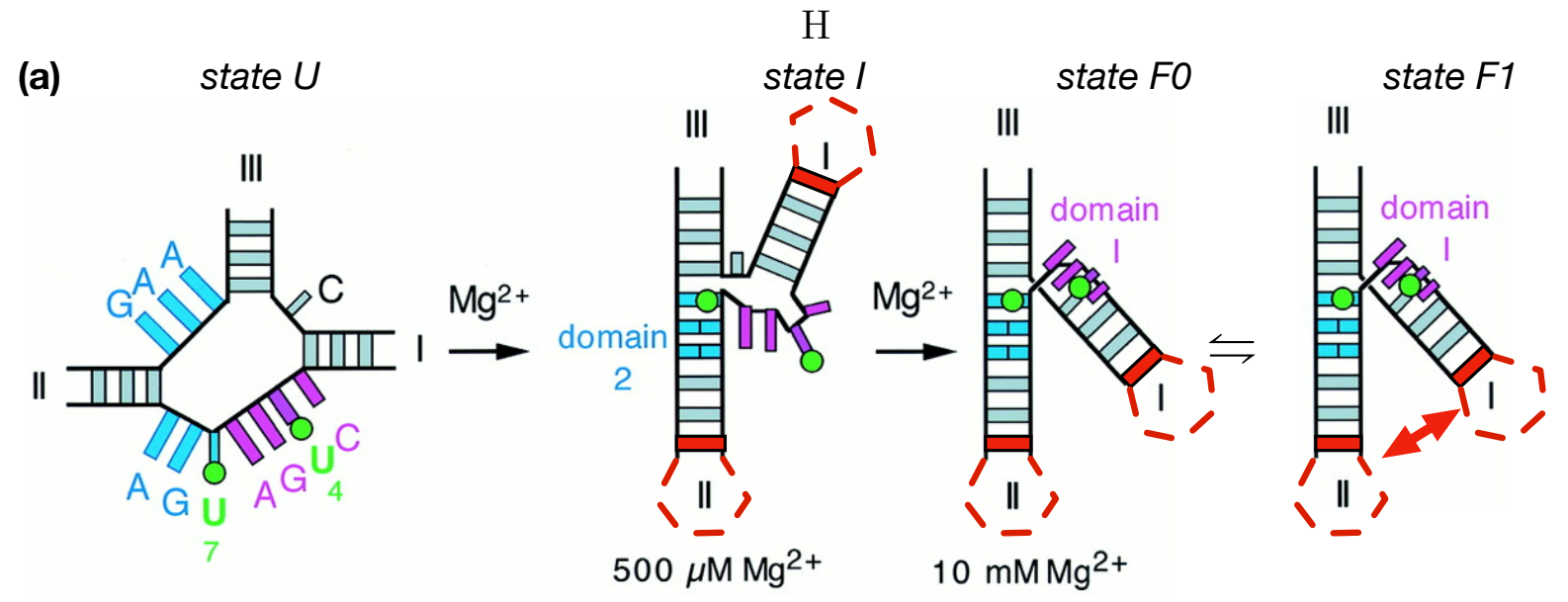

(b)
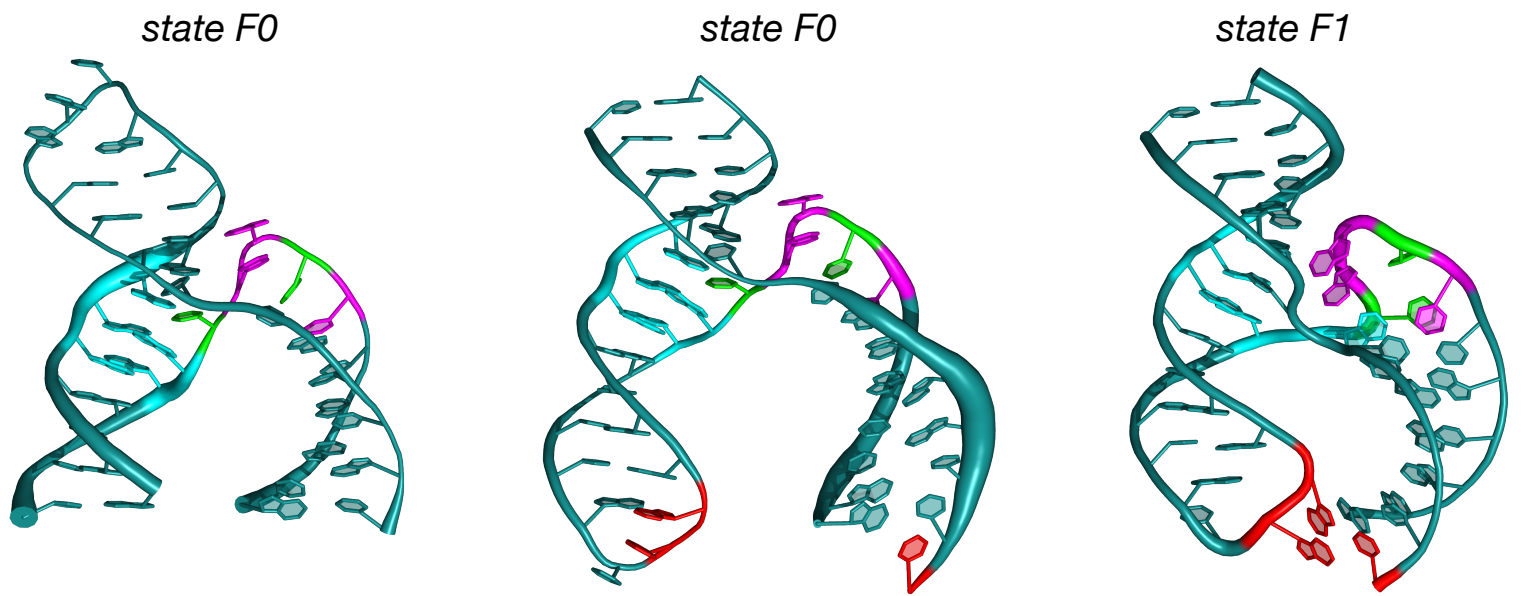

Figure 3: Folding kinetics and conformational states of the catalytic core of the hammerhead ribozyme. (a) Schematic folding scheme for the transition from the unfolded state (U) to some partially folded intermediate (I) and to the folded state F0; an additional conformational change may occur through tertiary contacts (red arrow) between the extensions of the stem-loops from domains I and II found in full-length hammerhead RNAs (red dashed line); modified with permission from Hammann et al. (2001). .987 Copyright (2001) National Academy of Sciences. (b) 3D structures of the hammerhead ribozyme in its truncated form corresponding to the F0 state and its minimal full-length form corresponding to the F1 state. From left to right: the 3D structures were taken from PDB IDs: 299D, $991 \mathrm{HMH}, 107$ and 2QUS.108 The nucleotides from domain I (magenta) and from domain II (cyan) are brought close to each other during the folding into the I and F states; the nucleotides from those two terminal domains (red) can establish tertiary contacts (red arrow) that help to fold into the active conformation (F1) with an increased catalytic efficiency. The cartoon representation of the RNA backbone includes a variable width which is proportional to the B-factors. 
the 3'P terminus (Figure 4).

(a)

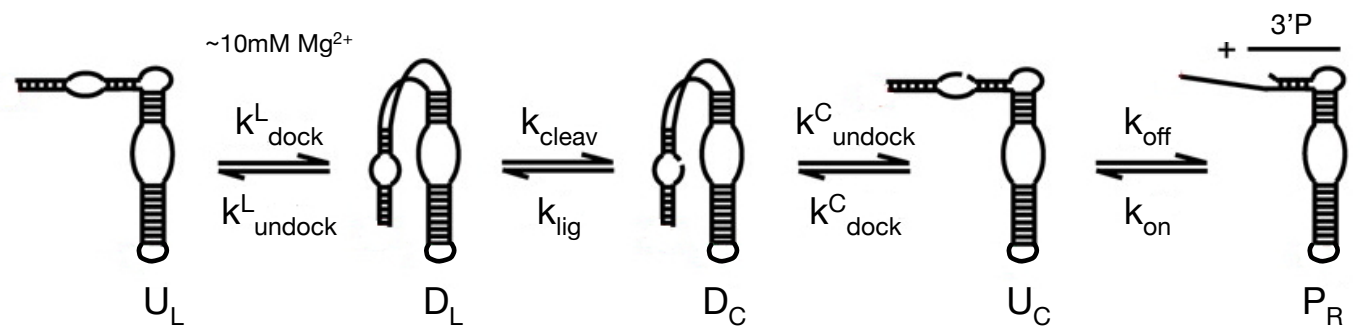

(b)

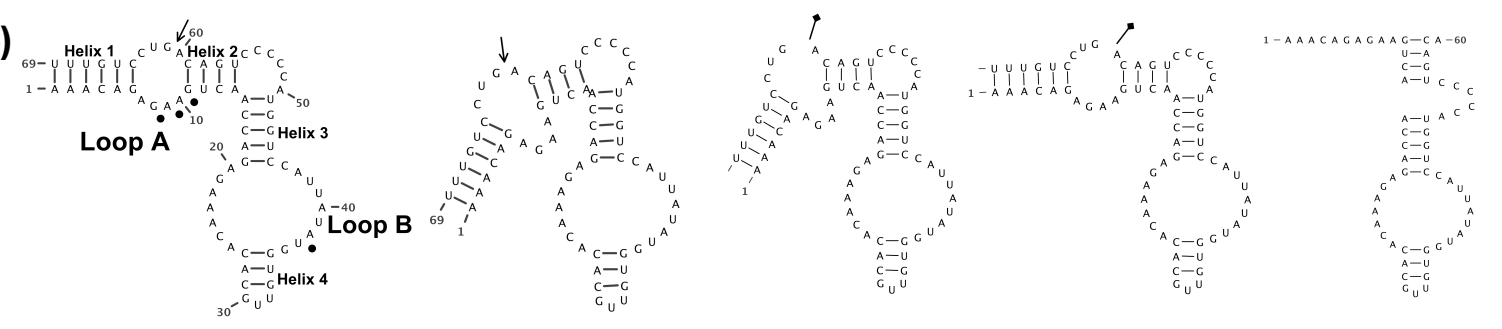

(c)
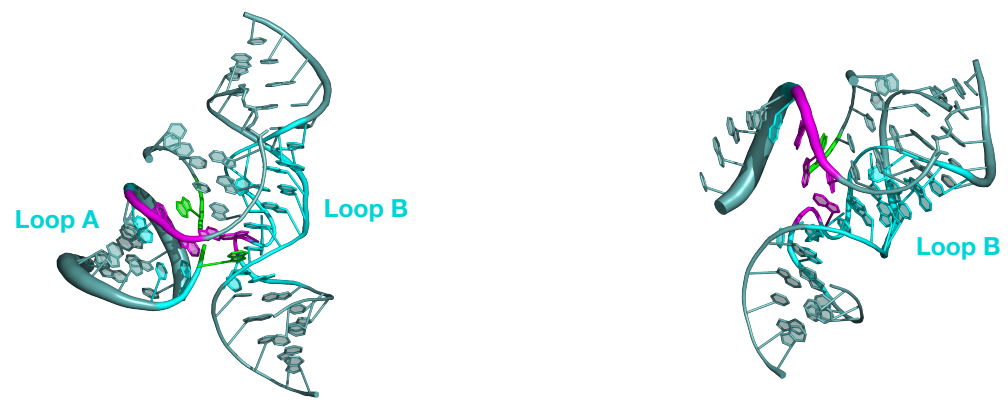

Figure 4: Multistep folding kinetics and catalysis by the hairpin ribozyme. (a) folding kinetics of the hairpin RNA; $U_{L}$ : undocked \& ligated, $D_{L}$ : docked \& ligated, $D_{C}$ : docked \& cleaved, $U_{C}$ : undocked \& cleaved, $P_{R}$ : product with 3'P released; modified with permission from Liu et al., (2007). ${ }^{114}$ Copyright (2007) National Academy of Sciences. (b) 2D structures of the hairpin ribozyme as found in the Tobacco Ringspot Virus satellite. The arrow indicated the cleavage site, the nucleotides marked by a dot correspond to nucleotides involved in the catalysis. The pin indicates the cleavage site after the transesterification reaction and before the release of the product. (c) 3D structures of the hairpin ribozyme (PDB ID: 2P7E) with a conformation corresponding to some intermediate between the $D_{L}$ and $D_{C}$ states (left) before the release of the product (right). The nucleotides from the Loops A and B are colored in cyan, those in green at the cleavage site and those in magenta correspond to the residues involved in the catalysis.

Mutagenesis and nucleotide analog interference mapping (NAIM) studies have shown that the nucleotides which are essential to the ribozyme activity reside in the two loops A and B from the two respective domains 1 and $2 \cdot \frac{115+119}{119}$ As a matter of fact, the domains 1 or 2 can be synthetized separately but none of them is catalytically active alone; however, the catalytic activity can be restored by reassembling the two separate domains which thus interact only 
through nonbonded interactions. $\frac{113}{113}$ The first structural data were obtained by NMR on the two separated domains. $\frac{120}{12}$ Since then, many 3D structures have been determined showing an irregular central motif including non-canonical base pairings, framed by regular helices, with an A-type geometry. 121

NMR studies on the structures of the isolated A and B segments showed that the structures of the isolated stems do not correspond to the active conformation of the ribozyme. The concerted mechanism of the reaction involves an alignment of the reactive atoms. ${ }^{122}$

The mutagenesis data suggest that a guanine residue downstream the cleaved position is absolutely essential. Mutagenesis and NAIM showed that four purine bases surrounding the active site cavity (G8, A9, A10, and A38) have functional groups involved in catalysis (Figure 2(c)). Furthermore, the twisting of the substrate strand induced by the folding of $\mathrm{A}$ and $\mathrm{B}$ allows the alignment of reactive atoms. The reaction mechanism is mediated by nucleobases through a general acid-base catalysis

During conformational rearrangements of the molecule, this nucleotide $(\mathrm{G}+1)$ from helix A is bulged out, but then, a part of the stem B specifically surrounds it, forming a pocket whose floor is constituted by a cytidine residue (C25) which establishes a base-pairing with $\mathrm{G}+1$. The interactions within the $\mathrm{G}+1$ attachment pocket represent about half of the free energy of folding. $112[123 \mid 124$

\subsection{Varkud satellite ribozyme of Neurospora (VS)}

The VS ribozyme of Neurospora is the largest known nucleolytic ribozyme. It was found to be embedded in VS RNA which is a long non-coding RNA that exists as a satellite RNA in mitochondria of Varkud-1C and few other strains of Neurospora. VS ribozyme contains features of both catalytic RNAs and group I introns. $\underline{66}$ The VS ribozyme has both cleavage and ligation activities performed efficiently in the absence of proteins. VS ribozyme undergoes horizontal gene transfer with other Neuropora strains.

VS ribozymes have very few in common with other nucleolytic ribozymes in terms of 
size and structure. However, they share some general common features with the hairpin ribozymes. The VS ribozyme undergoes major rearrengements during the folding of the active conformation that include changes in the RNA secondary structure. ${ }^{125 \mid 126}$ As in the hairpin ribozyme, tertiary interactions are involved during the folding in the presence of divalent metal ions; one of these well-studied interactions is a magnesium-dependent loop/loop pairing between the stem-loops I and $\mathrm{V} . \underline{127 \mid 128}$ In the reaction pathway of the hairpin ribozyme, several states were isolated and characterized. In the case of the VS ribozyme, the kinetic model of the reaction pathway is much more complex due to the size of the RNA with a hierarchical folding path. $\frac{129}{129}$ The role of nucleobases as catalysts was detected using different approaches: mutagenesis, $\frac{130}{2 K a}$ measurements $\frac{131}{131}$ and NAIM. $\frac{132}{12}$ Altough the topology of the active site is different in the two ribozymes, a comparison of the available data suggests they have a very similar reaction mechanism (Figure $2 \mathrm{c}$ and $2 \mathrm{f}$ ). 133

\subsection{RNA viruses and the HDV ribozyme}

Most of RNA viruses are plant viruses and possess ribozyme activity that participates in their multiplication. The first to have been characterized is the satellite RNA of Tobacco ringspot virus (sTRSV), then the HDV ribozyme, that is associated with Hepatitis B virus. The RNA of HDV adopts a pseudoknot structure. This ribozyme that can perform autocleavage 100 times faster than other hammerhead ribozymes is therefore the most efficient natural ribozyme known. It is very stable, its optimal cleavage temperature is $65^{\circ} \mathrm{C}$ and it is active up to $80{ }^{\circ} \mathrm{C}$.

Most of the reaction mechanisms of self-cleaving ribozymes involve nucleobases in some general acid/base catalysis (Figure 2). It also applies in the case of the HDV ribozyme where a protonated cytosine was first proposed as a catalyst to facilitate the departure of the leaving group. $\stackrel{134}{ }$ The exact role of divalent metal ions in the catalysis was unclear since monovalent ions could substitute $\mathrm{Mg}^{2+}$ while preserving some catalytic activity. However, the catalytic efficiency was reduced by two orders of magnitude. ${ }^{135}$ Further studies confirmed the role of 
the $\mathrm{C} 75$ protonated cytosine as a catalyst ${ }^{136}$ and a potential role of $M g^{2+}$ to induce a pKa shift facilitating the protonation of $\mathrm{C} 75$ (Figure $2 \mathrm{~b}$ ) ${ }^{137}$ In the more recent studies, $M g^{2+}$ appears to act directly or indirectly in the activation of the 2 'OH nucleophile ${ }^{138 / 139}$ and/or in the conformational switches required for the ribozyme activation. $\frac{75}{7}$

\subsection{The riboswitch ribozyme glucosamine-6-phosphate (glmS ri- bozyme)}

The glmS ribozyme is an RNA structure that resides in the 5' untranslated region (UTR) of the mRNA transcript of the glmS gene. This RNA regulates the expression of the glmS gene by responding to concentrations of a specific metabolite, glucosamine 6 phosphate (GlcN6P), in addition to catalyzing a self-cleaving chemical reaction upon activation. $\frac{62}{6 h i s}$ cleavage leads to the degradation of the mRNA that contains the ribozyme, and lowers production of GlcN6P. The glmS gene encodes for an enzyme glutamine-fructose-6-phosphate amidotransferase, which catalyzes the formation of GlcN6P, a compound essential for cell wall biosynthesis, from fructose-6-phosphate and glutamine. Thus, when the GlcN6P levels is high, the glmS ribozyme is activated and the mRNA transcript is degraded but in the absence of GlcN6P the gene continues to be translated into glutamine-fructose-6-phosphate amidotransferase and GlcN6P is produced. GlcN6P is a coenzyme for this cleavage reaction, as it directly participates as an acid-base catalyst. 140 Site-directed mutagenesis on the G40 residue of the catalytic center of this particular ribozyme allowed Klein et al. (2006) to demonstrate that this nucleotide plays a crucial role as a general base in the reaction. For this reason, its catalytic mechanism is often compared to that of the HDV ribozyme where GlcN6P coenzyme plays the same role than the protonated cytosine $\mathrm{C} 75$ as a catalyst (Figure 2b and 2p). 141

As in many other self-cleaving ribozymes, metal ions play a role in the folding of the glmS ribozyme but they were not attributed any other specific role. ${ }^{90}$ However, an earlier study suggested some alternative role of divalent ions on the overall apparent pKa of the ribozyme 
self-cleavage $\frac{142}{}$ A recent study confirms the role of $M g^{2+}$ in the pKa shifting of the guanine G40 as well as in the stabilization of the negative charge of the phosphate group. $\frac{73}{2}$ Divalent metal ions seem to operate in a similar way in both the glmS and hammerhead ribozymes (Figure 2d and 2e).

\subsection{The Ribosome}

The ribosome is a ribozyme. $\frac{143}{14}$ a pionneering contribution, Francis Crick (1968) claimed that the primitive ribosome could have been made entirely of RNA. Several years later, Steitz and Moore revealed that, indeed, the modern ribosome is a ribozyme suggesting that RNA, was the first macromolecular catalyst. 144 Ada Yonath (2009) $\frac{145}{14}$ proposed the structural nature of the protoribosome that is still present in the modern ribosome. The 23S RNA contained in the large ribosomal subunit is sufficient to catalyze the formation of the peptide bond during protein synthesis. The active site where the peptide bond is formed, is composed entirely of RNA, and is deprived of all protein elements. These latter elements positioned on the exterior of the cleavage site, only maintain the entire structure together.

\section{Why Pressure ?}

There are two kinds of reasons for which hydrostatic pressure is used to study structurefunction relationships in biomacromolecules and especially ribozymes. One is that pressure can provide valuable information about their structural organization and the mechanisms of the biochemical reactions that they catalyze. The other one is that, as discussed above, it has been proposed that ribozymes could have played an important role in prebiotic chemistry and the early steps of the development of life on earth, particularly in the hypothesis that prebiotic chemistry and early developments of life occured around the deep-sea vents or hydrothermal surface sites. $\frac{22|39| 44|49| 146] 148}{10}$ In this hypothesis, the range of pressure to be considered goes from 1 to 1100 bar since the deepest oceanic floor, the Marina Tranch, 149 
close to Japan is at minus 11,000 meters, on the basis that the hydrostatic pressure increases by 1 bar every ten meters.

\subsection{Pressure effects on cell physiology}

The influence of pressure on the biomacromolecules present within the cells has some various and often deleterious effects on the metabolism and physiology of these cells or the organisms they belong to (Table 1). ${ }^{39[150 \mid 151}$ Gene expression is influenced either negatively or positively and in many organisms one observes, not only the induction of already known genes coding for general stress-shock proteins but also of genes specifically involved in the pressure-stress. In most organisms, prokaryotes and eukaryotes; the rates of transcription and translation are decreased, the latter being mainly due to the dissociation of the ribosomes. This is associated to a slowing down of the cellular cycle. Exposure of living Hela cells to high pressure allowed Rousselet et al. (2001) ${ }^{152}$ to show that their division was impared through a negative influence on the microtubules nucleation by the centrioles. In addition, pressure reduces the membrane fluidity, in relation with a higher packing of the fatty acids. $\frac{153}{15 s}$ a consequence, the membrane becomes less permeable to water molecules. Cell walls and cytoskeleton are also affected. Pressure provokes the acidification of the cytoplasm and vacuoles, an effect which results from an influence on the dissociation constant of $\mathrm{H}_{2} \mathrm{CO}_{3}$

and $\mathrm{H}_{2} \mathrm{PO}_{4}{ }^{-}$due to the negative $\Delta \mathrm{V}$ associated to the exposure of additional charged groups to the solvent. 







\subsection{Adaptations to high pressure}

Many organisms from bacteria to vertebrates are living in high pressure environments (ocean bottom, hydrothermal deep-sea vents, terrestrial deep sites, etc) and are adapted to them. In deep-sea vent this adaptation is coupled, in a complex way, to the adaptation to high temperature. Two kinds of organisms are able to thrive under pressure: the so-called piezophiles and piezotolerent species. The first ones live constantly under pressure, fully adapted to it but unable to grow at atmospheric pressure, while the second ones are mesophilic organisms adapted to live under pressure but still able to do it at atmospheric pressure and this diversity is related to the degree of pressure. On the basis of the known effects of pressure on biological molecules several types of adaptation can be predicted: like the change of pKa of some important groups and changes in the nature of the aminoacids present at the surface of proteins. For instance, the polarity of the environment of a charged group whose pKa is important, can be changed in order to compensate the effect of pressure on this pKa; or some amino-acid substitutions in interacting interfaces to counter the negative influence of pressure. This biological adaptation is a complex and plurifactorial process involving several aspects such as modifications of gene expression, changes in membranes composition and modifications of the respiratory system. It is generally associated to numerous mutations ${ }^{150}$ which were shown to increase the number of hydrophobic interactions in the proteins, a modification which is also involved in thermophilicity ${ }^{154}$ In general, the expression of the genes coding for the heat-shock proteins such as Hsp104, GroEl and DnaK is largely enhanced. This is also the case of the genes involved in the metabolism of carbohydrates. In contrast, one observes frequently a decrease of the expression of the genes involved in the cell cycle and the biosynthesis of proteins. In relation with this the uptake of tryptophan is reduced in yeast. $\frac{155}{15}$ Interestingly, in several piezophilic bacteria it appeared that the change in some genes expression relies on the existence of alternative open reading frames. ${ }^{156}$ The acidification of the cytoplasm appears to play a role in this regulation of gene expression. This acidification is due to the deprononation of various molecules like $\mathrm{H}_{2} \mathrm{PO}_{4}^{-}$and $\mathrm{H}_{2} \mathrm{CO}_{3}$ 
and the negative $\Delta \mathrm{V}$ associated with these reactions. $\frac{157}{15}$ The adaptation to high pressure involves also a change in the population of fatty acids in the membranes which contain a higher proportion of unsaturated fatty bacids,rendering these membranes more fluid. $\frac{153 \mid 158}{15}$ This modification changes the properties of receptors and permeases. Concerning the respiratory system, in Shewanella bentica two pressure-regulated C-type cytochromes were isolated. They are coded for by genes whose expressions are differently sensitive to pression. $\frac{159}{1}$ The adaptation of vertebrates to deep-sea environments involves some specific protein modifications. This is the case of actin: Swezey and Somero (1982) of its polymerization in a series of fishes and showed that its adaptation to high pressure results from two kinds of structural modifications. One is a change in the tertiary structure of the actin monomers. The second one is an increase in the proportion of ionic interactions between the monomers for their polymerization.

\subsection{Pressure effects are based on volume changes}

The influence of pressure on the structure and properties of biological macromolecules in solution has been largely investigated in the case of proteins. 161 These studies showed that pressure exerts different influences on their structure. To begin with it favors the dissociation of ionic bonds, on the basis of the electrostriction which results from the interaction of water molecules with the liberated charged groups (see below). The same effect will tend to dissociate oligomeric proteins. Due to the very small $\Delta V$ associated with the formationdisruption of hydrogen bonds, pressure can have only a small positive or negative influence on these bonds in proteins, depending particularly on the polarity of their environment. On hydrophobic interactions the effect of pressure is more complex. It has a negative influence due to the fact that the establishment of these interactions is accompanied by a positive $\Delta V$. However, pressure has a positive influence on the stacking interactions between aromatic rings. $\frac{165[168}{16}$ Van der Walls interactions which play an important role in the tertiary structure of proteins are supposed to be enhanced by pressure since it tends to increase 
their packing. This is one of the aspects of the largely discussed compressibility of proteins which results also from expulsion of water molecules from their internal cavities. This is an important parameter since these cavities appear to play a significant role in protein structure-function from the mesoscopic scale (liquid-liquid phase separation) $\frac{167}{10}$ the micro-

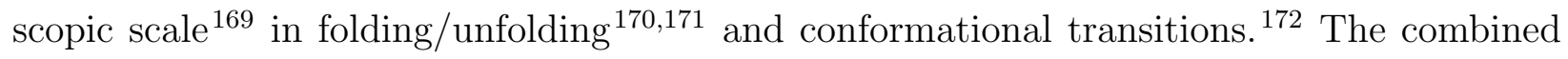
effects of all these properties lead to the denaturation of the proteins in solution. These effects are based on volume changes directed by the universel law PV=RT and the law of Le Chatelier. In any conditions, the pressure will favor the conformation of the macromolecule for which its solution occupies the smallest volume. In the case of an equilibrium between two conformations, the pressure will favor the side of the equilibrium for which the volume of the solution is the smallest. These rules govern a number of processes in the cell that are associated with molecular functions of the macromolecules such as association/dissociation of protein subunits, ligand binding, and others described on Figure 5. Pressure can induce volume changes and alter a number of molecular properties such as: hydration-dehydration, pKa shift of ionisable groups, disruption of ionic bonds, etc. In return, these alterations can impact the macromolecular properties. For example, the equilibrium between the association/dissociation of subunits is altered under high pressure; changes in the molecular properties such as the disruption of ionic bonds and/or the pKa shift of ionisable groups could displace the equilibrium. The details of the possible relationships between molecular properties and macromolecular functions are indicated in Figure 5. At high pressure these effects are often responsible for the denaturation of the macromolecule by unfolding and lead to some alterations of the cellular components and in fine to major cellular dysfunctions as listed previously (Table 1). A tight relationship also exists between pressure and molecular crowding: a crowded environment was reported to inhibit the protein unfolding of staphylococcal nuclease under high pressure. ${ }^{173}$ As for pressure, the crowding favors the reaction that reduces the net volume where the structures of macromolecules are more ordered and compact. ${ }^{174}$ Both pressure and molecular crowding have the ability to modulate the hydration 
of macromolecules. In the unfolding process, part of the influence of pressure can be due to the penetration of water molecules into the small cavities present into the macromolecular matrix and to the very small compressibility of these biomacromolecules in solution. $175 \mid 176$

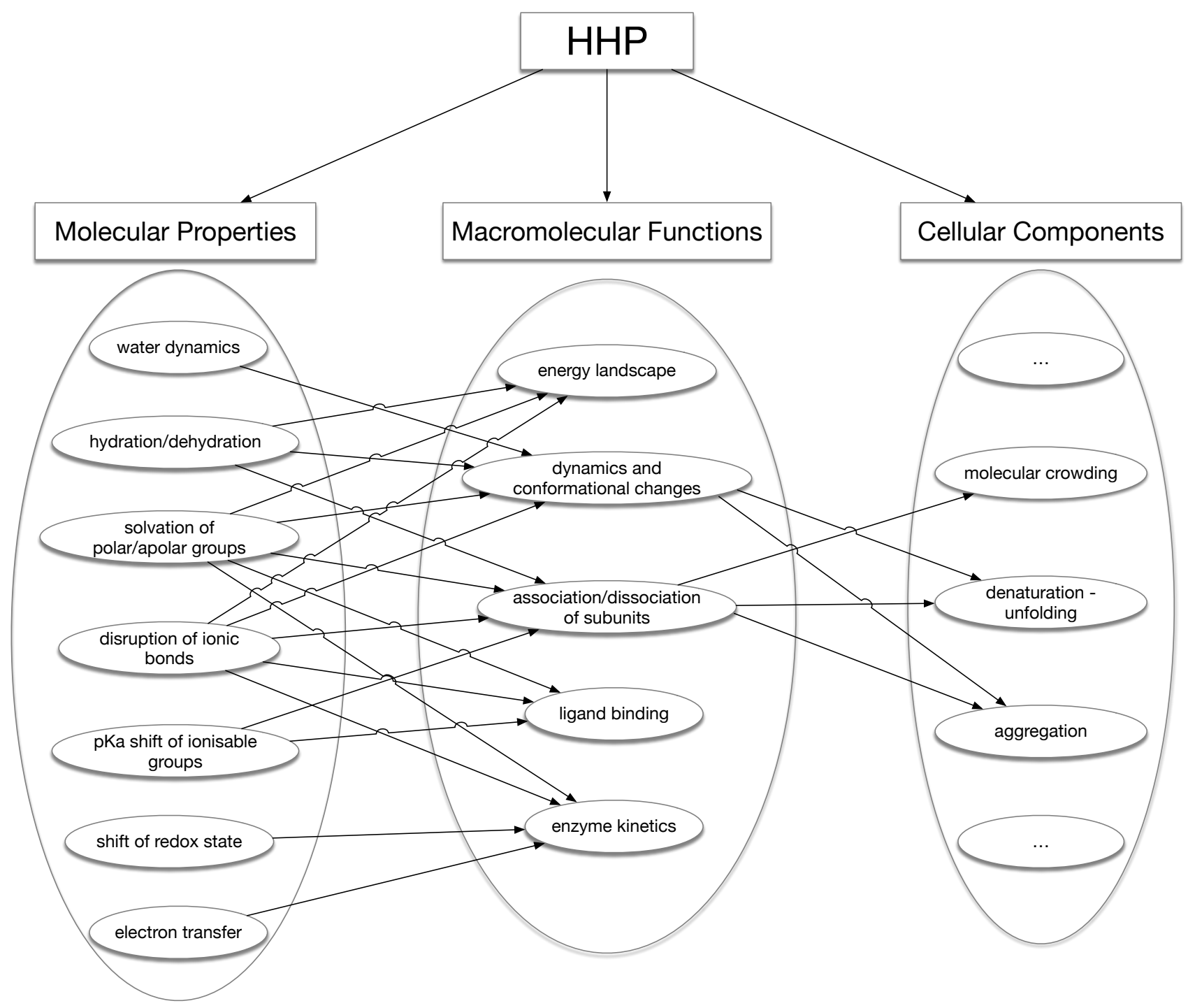

Figure 5: Impact of high hydrostatic pressure (HHP) on macromolecular properties and functions, and on cellular components.

It must be recalled that in addition to these effects and for the same reasons, pressure will also affect the $\mathrm{pH}$ of the solvent, as well as its dielectric constant, parameters which, in turn, will also affect the structure and properties of the biomacromolecules in solution. Pressure has also a small effect on the viscosity of the aqueous solution. High pressure, 
especially when it is associated with high temperature has also some specific effects on the structure of water. It can promote the appearance of some small spots of supercritical water, an apolar form of dimeric water. This supercritical water presents an elevated ability to dissolve apolar molecules or metabolites including those involved in prebiotic chemistry, thus favoring chemical reactions between them. ${ }^{177}$ On this basis, the environment of deep-sea vents will favor reactions between apolar precursors of prebiotic chemistry. $\frac{178 \mid 179}{}$ Over the past decades, different types of apparatus were devised in order to undergo under pressure all the physico-chemical investigations usually employed to study the structure and mechanisms of biomacromolecules. To begin with, fermentors were developed to grow under pressure the microorganisms which thrive under these conditions like those living in or around the deepsea vents. Enzyme kinetics can be followed in reactors in which samples can be taken without relieving the pressure ${ }^{180}$ and using stopped-flow apparatus. $\frac{181}{}$ All kinds of spectroscopy, absorption, fluorescence, Raman as well as NMR can be measured under pressure. More specifically, an incubator mimicking the conditions which prevail around deep-sea vents has been developed by Kawamura (2017). ${ }^{182}$ Even crystallographic structures can be determined under pressure. 183

\subsection{Electrostriction}

The phenomenon of electrostriction is responsible for some effects of pressure. That results from the fact that when a positive or negative charge is exposed to the solvent, the water molecules tend to pack around this charge by their complementary polar groups (Figure 6).

This effect is very strong. The first shell of water molecules around the charge is submitted to a pressure of 32,000 bar and one mole of water occupies only $15 \mathrm{ml}$. At the level of the second shell these parameters are 7,700 bar and $15.6 \mathrm{ml}$. Thus, the reaction volume or $\Delta V$ associated to this process of electrostriction is $-3 \mathrm{ml} / \mathrm{mol}$. The consequence is that pressure tends to expose the charged groups of the macromolecule to the solvent, including by disrupting the internal ionic bonds, with all the consequences that this will have on its 



Figure 6: Electrostriction around charged groups exposed to the solvent in proteins and nucleic acids.

structure and properties. The third shell of water molecules is not affected and belongs to the bulk solvent. For more examples, the values of activation volumes are available in the literature for a series of organic compounds, $\stackrel{184}{,}$ and for inorganic reactions. $\frac{157 \mid 185}{1 n}$ the case of biochemical reactions in proteins, a number of reference values are also available. $\frac{186}{10}$ Other kind of reactions have also been reported, for example: the protein unfolding $\frac{187}{10}$ the dissociation of single-stranded DNA binding proteins. $\frac{188}{18}$

\subsection{Influence of pressure on an equilibrium reaction}

In the case of any equilibrated reaction $\mathrm{A} \rightleftharpoons \mathrm{B}$ whose equilibrium constant is $\mathrm{K}$

$$
\mathrm{A} \underset{k_{2}}{\stackrel{k_{1}}{\rightleftharpoons}} \mathrm{B} \quad \mathrm{K}=\frac{k_{1}}{k_{2}}
$$

pressure will favor the side of the equilibrium for which the volume of the solution is the smallest. $\mathrm{K}$ is related to the change in this volume by the relation:

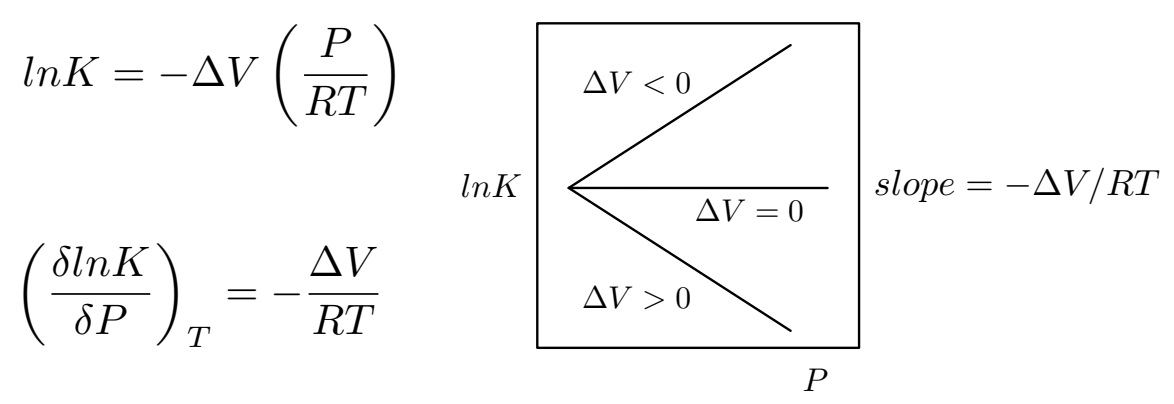

Figure 7: Influence of pressure on reaction equilibrium constant.

and in the graph representing the variation of the logarithm of $\mathrm{K},(\mathrm{LnK})$, as a function 
of the pressure $\mathrm{P}$, the slope is equal to $-\frac{\Delta V}{R T}$. So, if this $\Delta V$ is negative the equilibrium is shifted towards $\mathrm{B}$, but if $\Delta V$ is positive the equilibrium is shifted towards A (Figure 7).

\subsection{Influence of pressure on reactions catalyzed by enzymes}

The same principles apply to equilibrated reactions catalyzed by either proteic enzymes or ribozymes. In such a reaction of transformation of $\mathrm{A}$ into $\mathrm{B}$ and involving the transient formation of a transition state $A^{\neq}$;

$$
\mathrm{A} \stackrel{k_{1}}{\rightleftharpoons} A^{\neq} \rightleftharpoons \mathrm{B}
$$

two $\Delta V$ must be taken into account :

- the $\Delta V^{\neq}$of activation which is the difference between the volume of the solution of the starting molecule $\mathrm{A}$ and that of the transition state $A^{\neq}$.

- the $\Delta V$ of the reaction, that is the difference in volume of the solutions of the starting molecule $\mathrm{A}$ and of the product $\mathrm{B}$ as seen above.

If $\Delta V^{\neq}$is negative, pressure will accelerate the reaction, but if it is positive, something which is frequent, the rate of the reaction will decrease (Figure 8):

$$
\begin{array}{ll}
A \stackrel{k_{1}}{\rightleftharpoons} A^{\neq} \rightleftharpoons B & A^{\neq}=\text {transition state } \\
\Delta V^{\neq}=V A^{\neq}-V A & + \text { or }- \\
\left(\frac{\delta \ln k_{1}}{\delta P}\right)_{T}=-\frac{\Delta V^{\neq}}{R T} &
\end{array}
$$

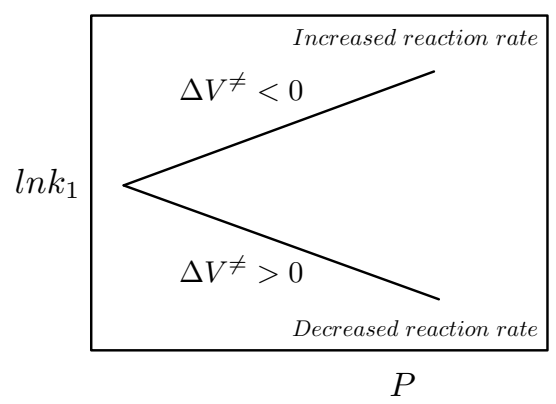

Figure 8: Influence of pressure on reaction rate constant.

\subsection{Osmotic Pressure}

It is of interest to complete the results obtained under the influence of hydrostatic pressure by osmotic pressure experiments, which provide information about the movements of water 
molecules in and out of the biomacromolecule in solution during the reaction that it catalyzes. This methodology has been devised by Parsegian et al. (1995). 189 The analysis considers two phases, the macromolecule, and the solvent and to add to the latter increasing concentrations of a solute which will increase its osmotic strength. The solute must be big enough to stay excluded from the macromolecule matrix but since the osmotic strength depends on the molarity of the solute, it must be small enough so that it does not lead to a significant increase of the solvent viscosity which would induce a parasite effect. Usually, the solute used is either polyethyleneglycol of an adequate degree of polymerization or dextran. The method allows to determine if there is an exchange of water between the macromolecule and the solvent during the reaction catalyzed by this macromolecule and to determine whether this movement goes in or out of the macromolecule (Figure 9). If the slope is positive it means that water molecules are liberated into the solvent. If it is negative, it means that additional water molecules bind to the macromolecule. In addition, the method allows to calculate the number of water molecules which are exchanged during this process by dividing $\Delta V_{w}$ by the volume of a water molecule.



Figure 9: Influence of osmotic pressure on reaction rate constant. Case of the release of water molecules to the solvent $\mathrm{k}$ is the Boltzman constant, $\mathrm{T}$ the Kelvin temperature; $k^{\pi}$ and $k^{0}$ the rate constants of the reaction under osmotic stress and under the control conditions respectively. 
Experiments using osmotic stress revealed an influence of water activity on macromolecular reactions and conformational transitions. For instance, DNA or RNA ligation by T4 DNA ligase is significantly accelerated in the presence of polymers in the solution that induce high osmotic pressure. $\frac{190}{19}$ The use of osmotic stress has allowed a detailed thermodynamic study of intermolecular interactions within a silk fibrin network and the identification of repulsive "hydration forces" between parallel DNA double helices. 191

\section{Influence of pressure on nucleic acids}

\subsection{DNA}

Pressure does not induce large-scale structural changes in nucleic acids. It is rather expected to stabilize the DNA double helix since the two contributions to its stability, base stacking and hydrogen bonds, are stabilized at high pressure ${ }^{176}$ but other factors are also involved. In fact, the double helix is not very sensitive to pressure. This is mainly due to the fact that the formation or disruption of hydrogen bonds is associated to a very small $\Delta V$, which can be either positive or negative, depending on the sequence and experimental conditions (ionic strength, temperature, etc). ${ }^{192}$ Under some conditions, pressure favors supercoiling of DNA. ${ }^{193}$ However, these effects are very complex, depending on temperature and ionic strength. Using synthetic double stranded DNA molecules, Dubins et al. (2001) ${ }^{194}$ showed that the effect of pressure depends not only on temperature but also on the melting temperature $T_{m}$ of the DNA sample. They found that these duplex were destabilized by pressure if their $T_{m}$ was less than to $50{ }^{\circ} \mathrm{C}$, but stabilized by pressure if it was more than $50{ }^{\circ} \mathrm{C}$, in accordance with some theoretical predictions. These observations are in accordance with the determined pressure-versus-temperature phase diagrams of melting of the different DNA samples used. It has been reported that pressure favors the B conformation of DNA and slows down its transition to the $\mathrm{Z}$ conformation. $\frac{195}{1 t}$ was hypothesized that some structural changes in nucleic acids induced by pressure could be driven by the transition of water 
structure from tetrahedral to a cubic-like geometry which is also accompanied by a negative volume change $(\Delta V) \underline{196 \mid 197}$

\subsection{RNA}

The influence of pressure on the ribosome has also been investigated on the basis that protein biosynthesis stops rapidly when E. coli cells are exposed to pressure (Table 1 ). $198 / 199$ Actually, as a function of pressure a correlation was found between the dissociation of the ribosomes into their $50 \mathrm{~S}$ and $30 \mathrm{~S}$ subunits and the cell death. ${ }^{200}$ Pressure provokes not only the dissociation of the ribosome into its $50 \mathrm{~S}$ and $30 \mathrm{~S}$ subunits but also that of these subunits into their components. 201

The tertiairy structure is particularly important for the properties of RNA and pressure has been reported to have some specific effects on this structure in tRNA (disruption of ionic interactions, bases stacking). At 6,000 bar phenylalanyl-tRNA and methionyl-tRNA can be charged by their specific aminoacids in absence of their aminoacyl-tRNA synthetases. The reaction takes place on the 3' end and appears to be specific. 202 This reaction occurs in absence of ATP and therefore does not need the activation of the aminoacid as adenylate. The authors speculate that pressure induces the formation of the same chargeable state of the tRNA than that promoted by its binding to the aminoacyl-tRNA synthetase. The

phenylalanyl-tRNA obtained by this way is the correct substrate for protein biosynthesis. 203 These effects of pressure can also be used to charge some tRNAs with non-natural aminoacids for experimental use. 204

\subsection{Loop-loop interactions, hairpins and bulges in RNA}

Several model systems of RNA motifs and domains have been used to evaluate the effect of hydrostatic pressure and extrapolate on its possible impact on large RNAs. As mentioned before, the pressure has an impact on the association/dissociation on protein subunits. In the case of RNA, the GAAA tetraloop-receptor was used to study the impact of pressure on 
loop-loop interactions which are recurrent tertiary interactions in many RNAs. The pressure has a small negative effect on the formation of the GAAA tetraloop-receptor interaction with a $\Delta V$ of 5 to $9 \mathrm{ml} /$ mole depending on the $M g^{2+}$ concentration which remains modest in comparison with what is observed in protein-protein or protein-nucleic acid interactions (50$260 \mathrm{ml} / \mathrm{mole}) .205$

Similarly, some very small RNA hairpin ribozymes are involved in several important biological processes. Several biophysical methods, including pressure were used to study their structural and thermodynamic properties. For this purpose, the small synthetic sRNA hairpin loop GCUUCGGC was labeled with fluorescent probes in 3' and 5' positions in order to use fluorescence energy transfer. $\frac{206}{2}$ Since the stem of the hairpin loop is very short (two base-pairs), we would expect that high pressure and temperatures $(\mathrm{P}=4000$ bar and $\mathrm{T} \geq$ $70{ }^{\circ} \mathrm{C}>\mathrm{Tm}$ ) would destabilize and unfold it at some point. However, the tertiary structure of this molecule is rather resistant to pressure and temperature. In fact, it appears to be able to adopt a series of different states which correspond to only partially unfolded states that are not present in standard conditions. $\underline{206}$

In contrast to DNA, RNA molecules naturally include unpaired or single-stranded regions. Bulges are particular cases of one or several unpaired nucleotide(s) within a double-stranded region or stem. Single nucleotide bulges confer some conformational flexibility to the stems: it can be stacked in the stem or looped out or in equilibrium between the two conformations. The conformations of such bulged nucleotides were studied in the case of an adenosine bulge (Figure 10). 207

The adenine base can flip out, a process which depends on the nature of the neighboring nucleotides. This movement not only changes the local conformation of the RNA but it also exposes its internal region to the solvent and ligands. It was estimated that the pressure increases the energy barrier for the transition from a stacked in to a looped out conformation. $\frac{207}{}$ As shown on some proteins, the pressure can reduce the molecular motions and alter its function. ${ }^{208}$ In these cases, the exposure to high pressure values increases the roughness 


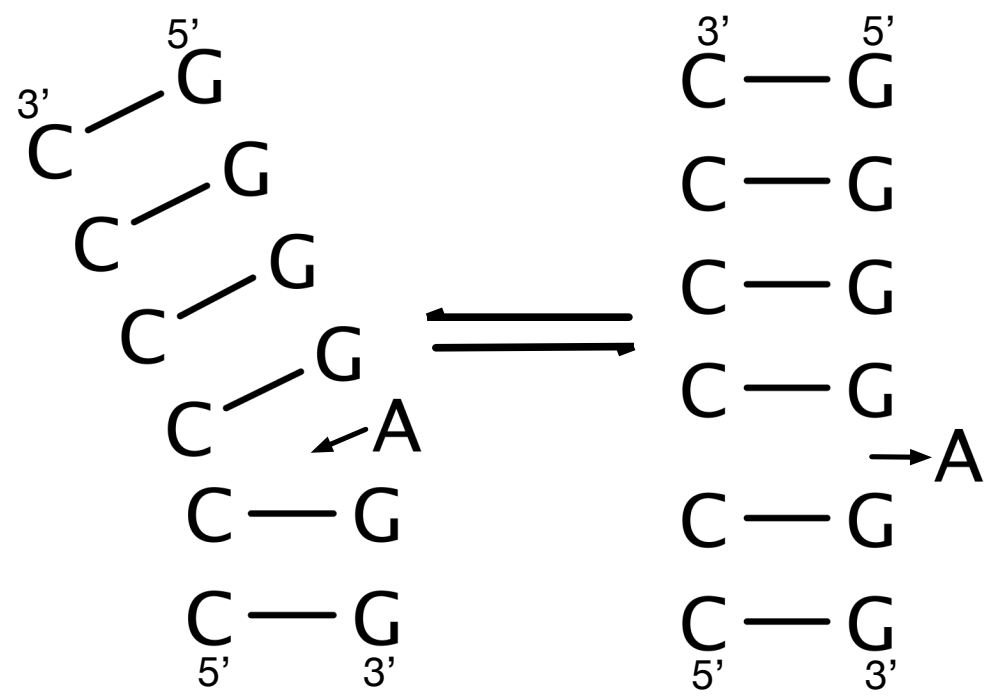

Figure 10: Structure of an adenine bulge with two conformations in equilibrium: stacked in (left) and looped out (right).

of the free energy landscape but it does not change the energy barriers.

The mechanism of action was attributed to the solvation with the presence of a larger number of water molecules around the stacked in conformation. ${ }^{207}$ Thus, reducing the molecular motions around the bulge nucleotide will shift the equilibrium towards the more solvated conformation. Since paired and unpaired nucleotides in RNA have different solvation patterns, 209 we might expect that pressure could have an impact on changes associated with transition between bulge in/out conformations (Figure 10). In the case of ribozymes, such conformational changes associated with folding and formation of the catalytically active conformation are common (Figure 3 and 4 ).

\section{$5 \quad$ High pressure studies of ribozymes}

We should recall that both hammerhead and hairpin ribozymes fold in presence of divalent metal ions $\left(\mathrm{Mg}^{2+}\right)$ which are required for the RNA to adopt its active conformation (Figure 3 \& Figure 11). They undergo several conformational changes along the reaction pathway leading to the cleaved products each of which can be affected by high pressure. The catalytic mechanisms involve in both cases some protonated/deprotonated nucleobases in a 
local environment that probably induces a pKa shift of those catalysts (Figure 2 e and $2 \mathrm{~d}$ ). High pressure is also susceptible to alter the processes involved in the chemical steps of the reaction.

\subsection{Hairpin ribozyme}

The wild type hairpin ribozyme isolated from the tobacco ringspot virus satellite, TRSV 8210 (Figure 4) has been used to study the effect of pressure on the kinetics of the self-cleavage reaction catalyzed by this ribozyme. This catalytic mechanism involves a structural rearrangement during which loops $\mathrm{A}$ and $\mathrm{B}$ come into close contact to form the catalytic site. 211 Pressure has a negative influence on the activity of this ribozyme. ${ }^{212}$ The plot of the logarithm of the rate constant of the reaction against pressure allowed to calculate a positive $\Delta V^{\ddagger}$ of activation of $34 \pm 5 \mathrm{ml} / \mathrm{mol}$ in accordance with the transient domain closure occurring during the reaction. The variation of the equilibrium constant of the reaction as a function of pressure allowed to calculate a reaction $\Delta V$ of $17 \pm 4.5 \mathrm{ml} / \mathrm{mol}$. These influences of pressure were fully reversible, confirming the interpretation that the decrease of activity was not due to an artefactual alteration of the structure of the RNA molecule but to a conformational change involved in the reaction. Osmotic shock experiments using PEG 400 or dextran 10000 as co-solute showed that the increase of osmolarity of the solvent increases the rate of the compaction which accompanies the formation of the transition state and that this domains closure results in the release of $78 \pm 4$ water molecules per mole of ribozyme. These results provide the following scheme for the self-cleavage reaction of this ribozyme.

The quantitative parameters obtained are of the same order of magnitude as those reported for reactions catalyzed by proteic enzymes. Interestingly, it has been shown by Schuabb et al., (2017) ${ }^{[72]}$ on the same ribozyme that, although pressure slows down the overall reaction, it accelerates the catalytic step of transesterification, an observation which is attributed to a local strengthening of interactions between the catalytic site and neighboring nucleobases. Rate constant determinations confirm that it is the docking of loops A and 


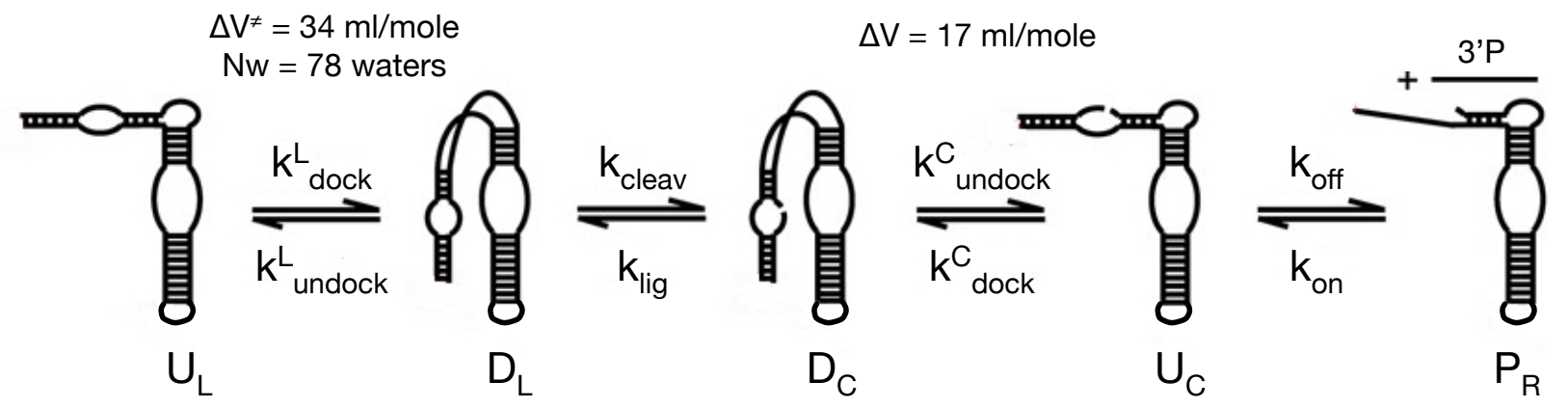

Figure 11: Volume changes and water molecules movements during the self-cleaving reaction of the hairpin ribozyme; modified from Liu et al. (2007). $\frac{114}{}$ Copyright (2007) National Academy of Sciences.

$\mathrm{B}$ which is retarded by pressure (Figure 4). Based on the crystallographic structure of the hairpin ribozyme $\stackrel{213}{21}$ Kumar and Marx used pressure in extensive molecular dynamics simulations focused along the reaction path of this ribozyme, including the pre-catalytic states, in order to obtain some information about the nucleobases involved in the reaction mechanism. 214 They could establish that guanosine 8 stabilizes the in-line arrangement which allows the nucleophilic attack of the scissile phosphate and that adenosine 38 is the proton donor to the O5' oxygen (Figure 22).

Besides, their investigation provides some information about the influence of pressure on the different steps of the reaction, confirming that the chemical cleavage step is significantly accelerated by pressure although the entire reaction is negatively affected. ${ }^{72[212}$ The higher rate of self-cleavage is conferred by a more favorable in-line configuration associated with the H-bonds formed in the active site with the nucleobases G8 and A38 that act as catalysts (Figure 2cc and Figure 12). A recent solvation model of the hairpin ribozyme suggests that the high-pressure regime pushes water molecules that penetrate into the interstitial spaces .215 On the other hand, the changes in the solvation induced by pressure turn out to slow down the kinetics of the reaction. $\frac{212}{2}$ Thus, we would expect that pressure destabilizes some of the docked states along the reaction pathway (Figure 11). Surprisingly, two studies on the effect of molecular crowding on the hairpin ribozyme reveal that it actually stabilizes the docked states. ${ }^{216 \mid 217}$ So, the pressure and molecular crowding have the same effect on the 




Figure 12: Elements of the catalytic site of the hairpin ribozyme. The colored atoms correspond to those involved in the chemical steps of the reaction and the annotations to the different roles of the catalysts as described previously (Figure 2).

accelerating of the catalytic reaction. However, they have opposite effects on the stabilization of the docked states. The kinetics of the hairpin ribozyme involves many different states (Figure 11) that cannot be all stabilized at the same time.

The use of the SELEX methodology allowed to obtain a modified active form of hairpin ribozyme whose activity requires the presence of adenine. 218 (Figure 13) This modified hairpin ribozyme (ADHR1) differs from the wild-type by the substitution of four nucleotides including adenine 38 which has been identified as a key residue for the reaction in the wild-type ribozyme. 214219

The influence of pressure on the kinetics of this modified ribozyme was extensively studied. ${ }^{220}$ Like in the wild-type ribozyme its activity depends not only on the presence of adenine but it also requires the presence of magnesium. Its specific activity is independent of its concentration, as expected from a unimolecular intramolecular reaction, indicating that this modified ribozyme does not form active dimers. This reaction is reversible but the pressure decreases the apparent equilibrium constant and the plot of $\ln \left(K_{e q}\right)$ against pressure provides 

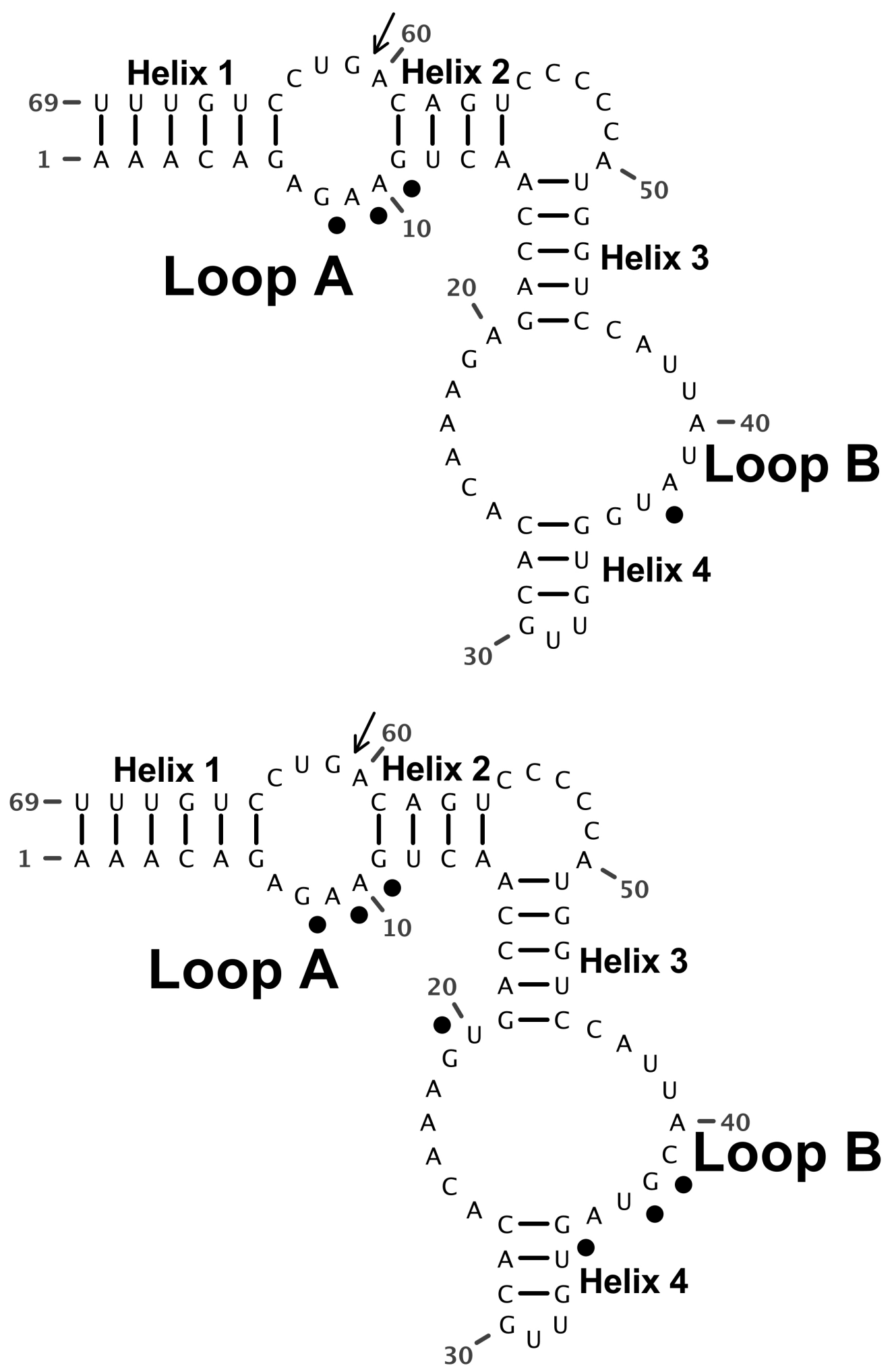

Figure 13: Structure of the adenine-dependent form of hairpin ribozyme. (a) the wild-type sequence. (b) the modified sequence. The dots, in Loop B, indicate the position of the substituted nucleotides. The arrow indicates the self-cleaving site. 
a $\Delta V$ value of $14 \pm 1 \mathrm{ml} /$ mole. The influence of pressure on the rate constant of the reaction indicates that its $\Delta V^{\neq}$of activation $(23 \pm 2 \mathrm{ml} / \mathrm{mol})$ is significantly smaller than that of the wild-type ribozyme $(34 \pm 5 \mathrm{ml} / \mathrm{mol})$. This difference suggests that the structure of this modified ribozyme might be shifted towards the transition state with respect to the ground state of the wild-type ribozyme. However this hypothesis is not supported by the results of the osmotic shock experiments which indicate that the formation of the transition state is accompanied by the release of $100 \pm 18$ molecules of water per molecule of the modified ribozyme, as compared to $78 \pm 4$ water molecules per molecule of the wild-type ribozyme.

\subsection{Hammerhead ribozyme}

Pressure was used to demonstrate that interactions of the hammerhead ribozyme with water are essential for its structure and activity. ${ }^{221}$ The influence of pressure on the hammerhead ribozyme has been investigated in the case of the ribozyme from Chrysanthemum chlorotic mottle viroid ${ }^{222}$ whose the 67 nucleotides structure is the following (Figure 14):



Figure 14: Hammerhead ribozyme from Chysantemum Chlorotic Mottle Viroid (CCHMVd). The arrow indicates the self-cleaving site. The nucleotide residues that are strictly or highly conserved in most natural HHRs are on a black background.

Like in the hairpin ribozyme, the self-cleavage activity of this ribozyme requires a domain 
closure between two distant loops (loops 1 and 2) (Figure 14). As shown below (Figure 15), the kinetics of the self-cleavage reaction showed a biphasic profile, and the deconvolution of this biphasic curve provided two exponential kinetics whose rate constants were $k_{\text {fast }}=$ $0.049 \mathrm{~min}^{-1}$ and $k_{\text {slow }}=0.0025 \mathrm{~min}^{-1}$ respectively. .222
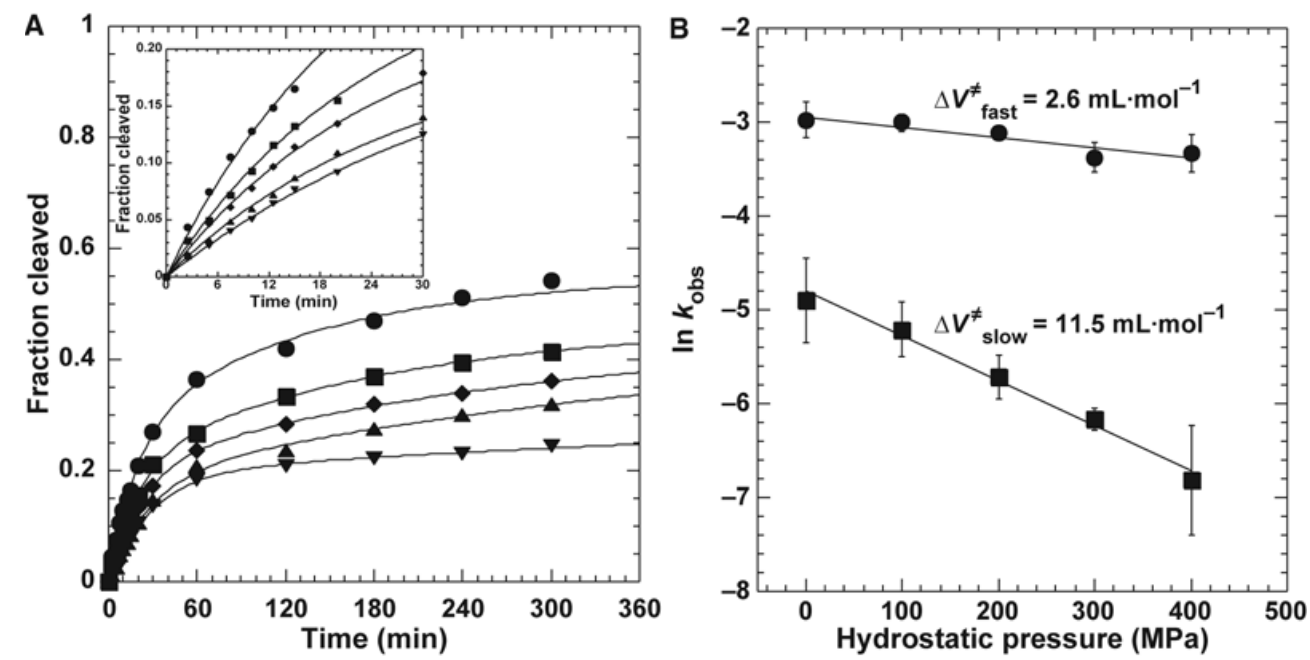

Figure 15: Kinetics (left) and $\Delta V^{\neq}$of activation (right) of the slow and fast populations of the ribozyme from CCHMVd. Reproduced with permission from Kaddour et al. $(2011)^{222}$ under CC BY License $)$.

These results were interpreted as indicating that the fast population of ribozyme molecules had already initiated the conformational change necessary for the catalytic activity. The influence of pressure was in accordance with this interpretation, the $\Delta V^{\neq}$of activation being $2.6 \mathrm{ml} / \mathrm{mol}$ in the case of the "fast" population and $11.5 \mathrm{ml} / \mathrm{mol}$ in the case of the "slow" population suggesting that the "fast" population has already undergone, at least partially, the domain closure and that the very small remaining $\Delta V^{\neq}$corresponds only to the last step of the formation of the transition state. Together with the large difference between the rate constants of the two molecular forms of this ribozyme, these results strongly suggest that the domain closure is the limiting step of the reaction that it catalyzes.

Some previous study on a minimal hammerhead motif showed that high hydrostatic pressure could rescue the catalytic activity of the ribozyme in absence of $M g^{2+.223}$ It was taken as a proof that $M g^{2+}$ does not play any direct role in the catalysis. For any minimal 
HHR motif that lacks the tertiary docking elements, the conditions for the catalysis are sub-optimal 101102224$]$ and it would be hazardous to draw any conclusion on that matter. However, it is consistent with the trend observed in the subsequent studies described above showing that pressure can contribute to accelerating the $\mathrm{Mg}^{2+}$-dependent folding into the active conformation.

\section{Concluding remarks}

Although the different types of hammerhead and hairpin ribozymes discovered and characterized over the past few years exhibit different 3D structures, their catalytic activities show very similar mechanisms involving domain closure and folding of their catalytic sites. The use of pressure to study these mechanisms revealed that the $\Delta V$ of the reactions or more precisely their $\Delta V^{\neq}$appear to be equivalent in both families of ribozymes (hammerhead and hairpin) while the environment of the catalytic site (Figure 2) and the global folds (Figures 3 and (4) are different. It is remarkable that both ribozymes exhibit similar responses under pressure, which must be of significance concerning the origin and/or evolution of these very peculiar RNAs.

Preliminary results show that, at least in the case of the hammerhead ribozyme, pressure decreases the $\Delta V^{\neq}$of activation, thus facilitating the formation of the transition state, suggesting that the negative influence of pressure on the rate of the reaction must concern a further step of this reaction but not the chemical step. The influence of temperature on the activity of the hammerhead ribozyme was also investigated. The rate of self-cleavage increases with temperature up to $60^{\circ} \mathrm{C}$, then there is competition between activity and denaturation of the RNA. However a very efficient protection of the ribozyme against degradation is observed for monovalent cations such as $\mathrm{Na}^{+}$or $\mathrm{K}^{+.225}$ Although there are similarities in the effect of pressure and molecular crowding on enzymes, it may differ in the case of ribozymes. The crowding effect tends to optimize the catalysis of group I and group II introns 


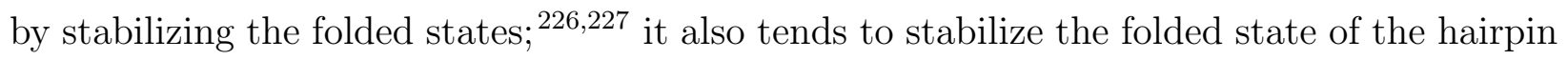
or hammerhead ribozymes. $216 \sqrt[217 / 228]{ }$

Altough only two self-cleaving ribozymes were subjected to studies about the effect of pressure on their catalytic activity, other ribozymes share some common catalysts with these two of them. The reaction mechanism of VS ribozymes is based on almost all the same catalysts than those of the hairpin ribozyme (Figure $2 \mathrm{c}$ and $2 \mathfrak{f}$ ). So, we might retreive some similar behavior for the VS ribozymes where pressure speeds up the chemical steps of the reaction. To a lesser extent, the hammerhead and glmS ribozymes have some common catalysts (Figure 2d and 2e) although a major difference is the implication of an external catalyst as coenzyme (GlcN6P) in the second one.

The hairpin and glmS ribozymes also share some unexpected features with respect to the use of coenzymes as catalysts. The hairpin ribozyme could be converted into a coenzyme-dependent ribozyme by in vitro selection of an adenine-dependent hairpin ribozyme (ADHR). ${ }^{8}$ The adenine ligand acts as an external catalyst and can be considered as a coenzyme; it replaces the adenine present at the catalytic site of the wild-type hairpin ribozyme. $\frac{220}{220}$ the opposite, the glmS ribozyme could be converted, using a similar approach, into a coenzyme-independent variant where the catalytic properties of the ligand are partially replaced by metal ions. $\frac{229}{22}$ Pressure studies might shed light on the involvement of water molecules in the cooperation co-enzyme-enzyme and differences in the relative solvation patterns.

The role of coenzyme or cofactors at all steps of the metabolism and their distribution within the three kingdoms of life suggest that a great variety of nucleotides was present at the origins of life. Several authors have underscored the possible presence of coenzymes before the appearance of the translation machinery: $\stackrel{4230}{~ c o e n z y m e s, ~ n u c l e o b a s e-m e t a l ~ c a t a l y s i s ~ a n d ~}$ ribozymes being fossil traces of past catalysts. It is even possible to consider that catalytic groups that were part of nucleic enzymes were incorporated into specific amino acids rather than being retained as coenzymes. This could be the case of imidazole, the functional group 
of histidine, whose present synthesis in the cell is triggered by a nucleotide.

The use of a coenzyme by the glmS ribozyme suggests a path for the transition from the RNA World where cofactor-dependent ribozymes may have evolved to bind amino acids noncovalently and then covalently thus driving the evolution of RNA aminoacylation. ${ }^{141}$ Some small RNAs carrying bulge nucleotides were found to be able to catalyze self-aminoacylation using aminoacyladenylates as substrates. ${ }^{231}$ More generally, bulge nucleotides represent potential binding sites for proteins or amino acids, based on the observation that proteinbinding RNAs possess a higher proportion of bulges. ${ }^{232}$ Thus, they could have played a role in prebiotic synthesis of polypeptides in the hypothetic RNA World. The influence of pressure on the process of adenine flipping out, in several synthetic small RNAs is rather complex but is compatible with this hypothesis. 207

Key questions in understanding catalysis in the adenine-dependent hairpin ribozyme (ADHR) representing a model for which ribozyme-mediated RNA catalysis is ligand induced like in the glmS ribozyme, include resolving how catalytic activity is realized and which structural rearrangements are associated with the cleavage process. The exogenous adenine cofactor is able to overtake essential functional properties in catalysis. In the case of glmS, the GlcN6P coenzyme is known to play multiple roles ${ }^{73174190}$ and its substitution seems to require two additional metals at the binding site.229

Studying the adenine-dependent hairpin ribozyme or the coenzyme-independent glmS ribozyme therefore enables the dissection of catalytic contributions to ribozyme activity. It revealed, for example, the particular role of the residue G65 in the catalysis by the wild-type ligand-induced glmS ribozyme. ${ }^{229}$ Both ribozymes represent models for evolutionary ancestors of chemistry essential for life,,$\underline{141212233}$ and thus, might provide insight into catalysis in an "RNA world". ${ }^{8229}$ The possible interconversion between coenzyme-dependent to coenzymeindependent ribozymes or vice-versa makes difficult to make a clear statement about which one would be the primordial copy and how it would have evolved. Generally, we expect that the current ribozymes to be more catalytically efficient than their primordial versions from 
the RNA world. It might not be the case depending on the cellular environment like for the hammerhead ribozyme. .53 Some higher degree of organization through self-assembly may also play a role in the modulation of the ribozyme activity. 234

A possible scenario is that life originated in the depth of the primeval ocean of the early Earth, under high hydrostatic pressure because the large amount of water would prevent against harmful radiation during pre-biotic chemistry. Viroids are sometimes considered as vestiges of the RNA world: $; \underline{50153}$ their multiplication requires three catalytic activities for the genome to be replicated: two of them were reproduced in artificial ribozymes (RNA polymerization and RNA ligation) while the third one is still present in one family of viroids (RNA cleavage by the hammerhead ribozyme).

Further studies of ribozymes under high pressure should be carried out. Ultimately, the effect of pressure might also help to elucidate the detailed catalytic mechanism of self-cleaving ribozymes.

\section{Author Information}

As Professor of Biochemistry and Molecular Evolution at Sorbonne University and researcher at the Institute of Systematics, Evolution and Biodiversity (ISYEB-CNRS-MNHN), MarieChristine Maurel devotes her research to the origins of life, mainly on the structures and functions of RNA, ribozymes and co-ribozymes as well as studies on Viroids. She directed the ANBioPhy laboratory (Nucleic Acids and Biophotonic, CNRS-UPMC) for several years at the interface of Biology, Physics and Chemistry. She was elected in 2014 to be a Fellow of the International Society for the Study of the Origin of Life (ISSOL).

Fabrice Leclerc is a CNRS investigator at the Institute for Integrative Biology of the Cell in University Paris Sud (France). He researches RNA bioinformatics and modeling and has contributed to the field of RNA biology through studying the RNA guide machinery that is responsible for the pseudo-uridylation of RNAs in archaea and on the RNA catalysis in 
the hammerhead ribozymes derived from viroids. Leclerc has provided reliable 2D and 3D structure-function models on RNA or RNA-protein complexes from archaea, viruses, and viroids.

Guy Hervé is Directeur de Recherche Emerite at the CNRS and the Université Pierre et Marie Curie in Paris. After his Doctorate he worked two years in the Biochemistry Department of Stanford University Medical School in California. He was Director of the Institute of Enzymology of the CNRS and President of the French Biophysical Society. Laureate of the French Academy of Sciences.

\section{Acknowledgement}

The authors thank CNRS and CNES for their support.

\section{References}

(1) Guerrier-Takada, C.; Gardiner, K.; Marsh, T.; Pace, N.; Altman, S. The RNA Moiety of Ribonuclease P is the Catalytic Subunit of the Enzyme. Cell 1983, 35, 849-857.

(2) Zaug, A. J.; Grabowski, P. J.; Cech, T. R. Autocatalytic Cyclization of an Excised Intervening Sequence RNA is a Cleavage-Ligation Reaction. Nature 1983, 301, 578583.

(3) Doudna, J. A.; Cech, T. R. The Chemical Repertoire of Natural Ribozymes. Nature 2002, $\underline{418,}, 222-228$.

(4) Maurel, M.-C.; Ninio, J. Catalysis by a Prebiotic Nucleotide Analog of Histidine. Biochimie 1987, 69, 551-553.

(5) Illangasekare, M.; Yarus, M. A Tiny RNA that Catalyzes both Aminoacyl-RNA and Peptidyl-RNA Synthesis. RNA 1999, $\underline{5}, 1482-1489$. 
(6) Roth, A.; Breaker, R. R. An Amino Acid as a Cofactor for a Catalytic Polynucleotide. Proc. Natl. Acad. Sci. U. S. A. 1998, 95, 6027-6031.

(7) Kun, Á.; Maurel, M.-C.; Santos, M.; Szathmáry, E. The Aptamer Handbook; WileyVCH Verlag GmbH \& Co. KGaA: Weinheim, FRG, 2006; pp 54-92.

(8) Meli, M.; Vergne, J.; Maurel, M.-C. In vitro Selection of Adenine-Dependent Hairpin Ribozymes. J. Biol. Chem. 2003, 278, 9835-9842.

(9) Gilbert, W. Origin of Life: the RNA World. Nature 1986, 319, 618-618.

(10) Rich, A. In Horizons in Biochemistry; Kasha, P. B. E., M., Ed.; Academic Press: New York, NY, USA, 1962.

(11) Lehman, N. The RNA World: 4,000,000,050 Years Old. Life 2014, 5, 1583-1586.

(12) Woese, C. R. The Genetic Code: the Molecular Basis for Genetic Expression, 1st ed.; York Harper \& Row: New York, 1967.

(13) Crick, F. H. The Origin of the Genetic Code. J. Mol. Biol. 1968, 38, 367-379.

(14) Orgel, L. E. Evolution of the Genetic Apparatus. J. Mol. Biol. 1968, 38, 381-393.

(15) Lazcano, A.; Miller, S. L. The Origin and Early Evolution of Life: Prebiotic Chemistry, the pre-RNA World, and Time. Cell 1996, 85, 793-798.

(16) Kitadai, N.; Maruyama, S. Origins of Building Blocks of Life: a Review. Geosci. Front. 2018, 9, 1117-1153.

(17) Callahan, M. P.; Smith, K. E.; Cleaves, H. J.; Ruzicka, J.; Stern, J. C.; Glavin, D. P.; House, C. H.; Dworkin, J. P. Carbonaceous Meteorites Contain a Wide Range of Extraterrestrial Nucleobases. Proc. Natl. Acad. Sci. U. S. A. 2011, 108, 13995-13998.

(18) Rothschild, L. J.; Mancinelli, R. L. Life in Extreme Environments. Nature 2001, 409, 1092-1101. 
(19) Veras, D.; Armstrong, D. J.; Blake, J. A.; Gutiérrez-Marcos, J. F.; Jackson, A. P.; Schäefer, H. Dynamical and Biological Panspermia Constraints within Multi-Planet Exosystems. Astrobiology 2018, 18, 1106-1122.

(20) Meadows, V. S. et al. Exoplanet Biosignatures: Understanding Oxygen as a Biosignature in the Context of Its Environment. Astrobiology 2018, 18, 630-662.

(21) Cataldi, G.; Brandeker, A.; Thébault, P.; Singer, K.; Ahmed, E.; de Vries, B. L.; Neubeck, A.; Olofsson, G. Searching for Biosignatures in Exoplanetary Impact Ejecta. Astrobiology 2017, 17, 721-746.

(22) Deamer, D.; Damer, B. Can Life Begin on Enceladus? A Perspective from Hydrothermal Chemistry. Astrobiology 2017, 17, 834-839.

(23) Baross, J. A.; Hoffman, S. E. Submarine Hydrothermal Vents and Associated Gradient Environments as Sites for the Origin and Evolution of Life. Origins Life Evol. Biospheres 1985, 15, 327-345.

(24) Arndt, N. T.; Nisbet, E. G. Processes on the Young Earth and the Habitats of Early Life. Annu. Rev. Earth Planet. Sci. 2012, 40, 521-549.

(25) Ruiz-Mirazo, K.; Briones, C.; de la Escosura, A. Prebiotic Systems Chemistry: New Perspectives for the Origins of Life. Chem. Rev. (Washington, DC, U. S.) 2014, 114, 285-366.

(26) Di Giulio, M. The Universal Ancestor and the Ancestor of Bacteria Were Hyperthermophiles. J. Mol. Evol. 2003, 57, 721-730.

(27) Weiss, M. C.; Sousa, F. L.; Mrnjavac, N.; Neukirchen, S.; Roettger, M.; NelsonSathi, S.; Martin, W. F. The Physiology and Habitat of the Last Universal Common Ancestor. Nat. Microbiol. 2016, 1, 16116. 
(28) Weiss, M. C.; Preiner, M.; Xavier, J. C.; Zimorski, V.; Martin, W. F. The Last Universal Common Ancestor Between Ancient Earth Chemistry and the Onset of Genetics. PLoS Genet. 2018, 14, e1007518.

(29) Miller, S. L.; Bada, J. L. Submarine Hot Springs and the Origin of Life. Nature 1988, 334, 609-611.

(30) Koonin, E. V.; Martin, W. On the Origin of Genomes and Cells within Inorganic Compartments. Trends Genet. 2005, 21, 647-654.

(31) Groussin, M.; Boussau, B.; Charles, S.; Blanquart, S.; Gouy, M. The Molecular Signal for the Adaptation to Cold Temperature During Early Life on Earth. Biol. Lett. 2013, 9, 20130608.

(32) Gogarten, J. P.; Deamer, D. Is LUCA a Thermophilic Progenote? Nat. Microbiol. 2016, 1, 16229.

(33) Brochier, C.; Philippe, H. Phylogeny: a Non-Hyperthermophilic Ancestor for Bacteria. Nature 2002, 417, 244-244.

(34) Xu, Y.; Glansdorff, N. Was Our Ancestor a Hyperthermophilic Procaryote? Comp. Biochem. Physiol., Part A: Mol. Integr. Physiol., Molecular \& integrative physiology 2002, 133, 677-688.

(35) Glansdorff, N.; Xu, Y.; Labedan, B. The Last Universal Common Ancestor: Emergence, Constitution and Genetic Legacy of an Elusive Forerunner. Biol. Direct 2008, $\underline{3}, 29$.

(36) Feller, G. Cryosphere and Psychrophiles: Insights into a Cold Origin of Life? Life $2017, \underline{7}, 25$.

(37) Merino, N.; Aronson, H. S.; Bojanova, D. P.; Feyhl-Buska, J.; Wong, M. L.; Zhang, S.; 
Giovannelli, D. Living at the Extremes: Extremophiles and the Limits of Life in a Planetary Context. Front. Microbiol. 2019, 10, 780.

(38) Cantine, M. D.; Fournier, G. P. Environmental Adaptation from the Origin of Life to the Last Universal Common Ancestor. Origins Life Evol. Biospheres 2018, 48, 35-54.

(39) Daniel, I.; Oger, P.; Winter, R. Origins of Life and Biochemistry under High-Pressure Conditions. Chem. Soc. Rev. 2006, 35, 858-875.

(40) Hazen, R. M.; Boctor, N.; Brandes, J. A.; Cody, G. D.; Hemley, R. J.; Sharma, A.; Yoder Jr, H. S. High Pressure and the Origin of Life. J. Phys.: Condens. Matter 2002, $\underline{14}, 11489-11494$.

(41) Poli, A.; Finore, I.; Romano, I.; Gioiello, A.; Lama, L.; Nicolaus, B. Microbial Diversity in Extreme Marine Habitats and Their Biomolecules. Microorganisms 2017, $\underline{5}, 25$.

(42) Fang, J.; Zhang, L.; Bazylinski, D. A. Deep-Sea Piezosphere and Piezophiles: Geomicrobiology and Biogeochemistry. Trends Microbiol. 2010, 18, 413-422.

(43) Nickerson, K. W. A Hypothesis on the Role of Pressure in the Origin of Life. J. Theor. Biol. 1984, 110, 487-499.

(44) Orgel, L. E. Prebiotic Chemistry and the Origin of the RNA World. Crit. Rev. Biochem. Mol. Biol. 2004, 39, 99-123.

(45) Ogasawara, H.; Yoshida, A.; Imai, E.; Honda, H.; Hatori, K.; Matsuno, K. Synthesizing Oligomers from Monomeric Nucleotides in Simulated Hydrothermal Environments. Origins Life Evol. Biospheres 2000, 30, 519-526.

(46) Powner, M. W.; Gerland, B.; Sutherland, J. D. Synthesis of Activated Pyrimidine Ribonucleotides in Prebiotically Plausible Conditions. Nature 2009, 459, 239-242. 
(47) DeGuzman, V.; Vercoutere, W.; Shenasa, H.; Deamer, D. Generation of Oligonucleotides under Hydrothermal Conditions by Non-Enzymatic Polymerization. J. Mol. Evol. 2014, 78, 251-262.

(48) Stairs, S.; Nikmal, A.; Bučar, D.-K.; Zheng, S.-L.; Szostak, J. W.; Powner, M. W. Divergent Prebiotic Synthesis of Pyrimidine and 8-Oxo-Purine Ribonucleotides. Nat. Commun. 2017, $\underline{8}, 15270$.

(49) Deamer, D. W.; Georgiou, C. D. Hydrothermal Conditions and the Origin of Cellular Life. Astrobiology 2015, 15, 1091-1095.

(50) Diener, T. O. The Viroid: Biological Oddity Or Evolutionary Fossil? Adv. Virus Res. 2001, $\underline{57}, 137-184$.

(51) Flores, R.; Gago-Zachert, S.; Serra, P.; Sanjuán, R.; Elena, S. F. Viroids: Survivors from the RNA World? Microbiology 2013, 68, 395-414.

(52) Pressman, A.; Blanco, C.; Chen, I. A. The RNA World as a Model System to Study the Origin of Life. Curr. Biol. 2015, 25, R953-63.

(53) Maurel, M.-C.; Leclerc, F.; Vergne, J.; Zaccai, G. RNA Back and Forth: Looking Through Ribozyme and Viroid Motifs. Viruses 2019, 11, 283.

(54) Ren, A.; Micura, R.; Patel, D. J. Structure-Based Mechanistic Insights into Catalysis by Small Self-Cleaving Ribozymes. Curr. Opin. Chem. Biol. 2017, 41, 71-83.

(55) Seith, D.; Bingaman, J. L.; Veenis, A.; Button, A. C.; Bevilacqua, P. C. Elucidation of Catalytic Strategies of Small Nucleolytic Ribozymes from Comparative Analysis of Active Sites. ACS Catal. 2017, $\underline{8}, 314-327$.

(56) Stahley, M. R.; Strobel, S. A. RNA Splicing: Group I Intron Crystal Structures Reveal the Basis of Splice Site Selection and Metal Ion Catalysis. Curr. Opin. Struct. Biol. 2006, 16, 319-326. 
(57) Pyle, A. M. Group II Intron Self-Splicing. Annu. Rev. Biophys. 2016, 45, 183-205.

(58) Zhao, C.; Pyle, A. M. Structural Insights into the Mechanism of Group II Intron Splicing. Trends Biochem. Sci. 2017, 42, 470-482.

(59) Persson, T.; Cuzic, S.; Hartmann, R. K. Catalysis by RNase P RNA: Unique Features and Unprecedented Active Site Plasticity. J. Biol. Chem. 2003, 278, 43394-43401.

(60) Nissen, P.; Hansen, J.; Ban, N.; Moore, P. B.; Steitz, T. A. The Structural Basis of Ribosome Activity in Peptide Bond Synthesis. Science 2000, 289, 920-930.

(61) Hang, J.; Wan, R.; Yan, C.; Shi, Y. Structural Basis of pre-mRNA Splicing. Science 2015, 349, 1191-1198.

(62) McCarthy, T. J.; Plog, M. A.; Floy, S. A.; Jansen, J. A.; Soukup, J. K.; Soukup, G. A. Ligand Requirements for glmS Ribozyme Self-Cleavage. Chemistry \& Biology 2005, 12, 1221-1226.

(63) Klein, D. J.; Ferré-D'Amaré, A. R. Structural Basis of glmS Ribozyme Activation by Glucosamine-6-Phosphate. Science 2006, 313, 1752-1756.

(64) Bonino, F.; Negro, F.; Baldi, M.; Brunetto, M. R.; Chiaberge, E.; Capalbo, M.; Maran, E.; Lavarini, C.; Rocca, N.; Rocca, G. The Natural History of Chronic Delta Hepatitis. Prog. Clin. Biol. Res. 1987, 234, 145-152.

(65) Lafontaine, D. A.; Norman, D. G.; Lilley, D. M. The Structure and Active Site of the Varkud Satellite Ribozyme. Biochem. Soc. Trans. 2002, 30, 1170-1175.

(66) Lilley, D. M. J. The Varkud Satellite Ribozyme. RNA 2004, 10, 151-158.

(67) Roth, A.; Weinberg, Z.; Chen, A. G. Y.; Kim, P. B.; Ames, T. D.; Breaker, R. R. A Widespread Self-Cleaving Ribozyme Class is Revealed by Bioinformatics. Nat. Chem. Biol. 2014, 10, 56-60. 
(68) Weinberg, Z.; Kim, P. B.; Chen, T. H.; Li, S.; Harris, K. a.; Lünse, C. E.; Breaker, R. R. New Classes of Self-Cleaving Ribozymes Revealed by Comparative Genomics Analysis. Nat. Chem. Biol. 2015, 11, 606-610.

(69) Ren, A.; Vušurović, N.; Gebetsberger, J.; Gao, P.; Juen, M.; Kreutz, C.; Micura, R.; Patel, D. J. Pistol Ribozyme Adopts a Pseudoknot Fold Facilitating Site-Specific InLine Cleavage. Nat. Chem. Biol. 2016, 12, 702-708.

(70) Mir, A.; Chen, J.; Robinson, K.; Lendy, E.; Goodman, J.; Neau, D.; Golden, B. L. Two Divalent Metal Ions and Conformational Changes Play Roles in the Hammerhead Ribozyme Cleavage Reaction. Biochemistry 2015, 54, 6369-6381.

(71) Chen, H.; Giese, T. J.; Golden, B. L.; York, D. M. Divalent Metal Ion Activation of a Guanine General Base in the Hammerhead Ribozyme: Insights from Molecular Simulations. Biochemistry 2017, 56, 2985-2994.

(72) Schuabb, C.; Kumar, N.; Pataraia, S.; Marx, D.; Winter, R. Pressure Modulates the Self-Cleavage Step of the Hairpin Ribozyme. Nat. Commun. 2017, $\underline{8}, 14661$.

(73) Zhang, S.; Stevens, D. R.; Goyal, P.; Bingaman, J. L.; Bevilacqua, P. C.; HammesSchiffer, S. Assessing the Potential Effects of Active Site $\mathrm{Mg}(2+)$ Ions in the glmS Ribozyme-Cofactor Complex. J. Phys. Chem. Lett. 2016, 7, 3984-3988.

(74) Bingaman, J. L.; Zhang, S.; Stevens, D. R.; Yennawar, N. H.; Hammes-Schiffer, S.; Bevilacqua, P. C. The GlcN6P Cofactor Plays Multiple Catalytic Roles in the glmS Ribozyme. Nat. Chem. Biol. 2017, 13, 439-445.

(75) Lee, T.-S.; Radak, B. K.; Harris, M. E.; York, D. M. A Two-Metal-Ion-Mediated Conformational Switching Pathway for HDV Ribozyme Activation. ACS Catal. catalysis 2016, $\underline{6}, 1853-1869$. 
(76) Suslov, N. B.; DasGupta, S.; Huang, H.; Fuller, J. R.; Lilley, D. M. J.; Rice, P. A.; Piccirilli, J. A. Crystal Structure of the Varkud Satellite Ribozyme. Nat. Chem. Biol. 2015, 11, 840-846.

(77) Gaines, C. S.; York, D. M. Ribozyme Catalysis with a Twist: Active State of the Twister Ribozyme in Solution Predicted from Molecular Simulation. J. Am. Chem. Soc. 2016, 138, 3058-3065.

(78) Gebetsberger, J.; Micura, R. Unwinding the Twister Ribozyme: from Structure to Mechanism. Wiley Interdiscip. Rev.: RNA 2016, $\underline{8}$, e1402.

(79) Nguyen, L. A.; Wang, J.; Steitz, T. A. Crystal Structure of Pistol, a Class of SelfCleaving Ribozyme. Proc. Natl. Acad. Sci. U. S. A. 2017, 114, 1021-1026.

(80) Zheng, L.; Mairhofer, E.; Teplova, M.; Zhang, Y.; Ma, J.; Patel, D. J.; Micura, R.; Ren, A. Structure-Based Insights into Self-Cleavage by a Four-Way Junctional Twister-Sister Ribozyme. Nat. Commun. 2017, $\underline{8}, 1180$.

(81) Sigel, R. K. O.; Pyle, A. M. Alternative Roles for Metal Ions in Enzyme Catalysis and the Implications for Ribozyme Chemistry. Chem. Rev. (Washington, DC, U. S.) 2007, 107, 97-113.

(82) Johnson-Buck, A. E.; McDowell, S. E.; Walter, N. G. Metal Ions: Supporting Actors in the Playbook of Small Ribozymes. Met. Ions Life Sci. 2011, 9, 175-196.

(83) Wedekind, J. E. Metal Ion Binding and Function in Natural and Artificial Small RNA Enzymes from a Structural Perspective. Met. Ions Life Sci. 2011, $\underline{9}$, 299-345.

(84) Leclerc, F. Hammerhead Ribozymes: True Metal Or Nucleobase Catalysis? Where is the Catalytic Power From? Molecules 2010, 15, 5389-5407.

(85) Mir, A.; Golden, B. L. Two Active Site Divalent Ions in the Crystal Structure of the 
Hammerhead Ribozyme Bound to a Transition State Analogue. Biochemistry 2016, $\underline{55}, 633-636$.

(86) Alam, S.; Grum-Tokars, V.; Krucinska, J.; Kundracik, M. L.; Wedekind, J. E. Conformational Heterogeneity at Position U37 of an All-RNA Hairpin Ribozyme with Implications for Metal Binding and the Catalytic Structure of the S-Turn. Biochemistry 2005, 44, 14396-14408.

(87) Young, K. J.; Gill, F.; Grasby, J. A. Metal Ions Play a Passive Role in the Hairpin Ribozyme Catalysed Reaction. Nucleic Acids Res. 1997, 25, 3760-3766.

(88) Boots, J. L.; Canny, M. D.; Azimi, E.; Pardi, A. Metal Ion Specificities for Folding and Cleavage Activity in the Schistosoma Hammerhead Ribozyme. RNA 2008, 14, $2212-2222$.

(89) Gong, B.; Chen, J.-H.; Bevilacqua, P. C.; Golden, B. L.; Carey, P. R. Competition Between $\mathrm{Co}(\mathrm{NH}(3)(6) 3+$ and Inner Sphere Mg2+ Ions in the HDV Ribozyme. Biochemistry 2009, $\underline{48}, 11961-11970$.

(90) Brooks, K. M.; Hampel, K. J. Rapid Steps in the glmS Ribozyme Catalytic Pathway: Cation and Ligand Requirements. Biochemistry 2011, 50, 2424-2433.

(91) Hiley, S. L.; Collins, R. A. Rapid Formation of a Solvent-Inaccessible Core in the Neurospora Varkud Satellite Ribozyme. EMBO J. 2001, 20, 5461-5469.

(92) Panja, S.; Hua, B.; Zegarra, D.; Ha, T.; Woodson, S. A. Metals Induce Transient Folding and Activation of the Twister Ribozyme. Nat. Chem. Biol. 2017, 13, 11091114 .

(93) Ki-Young Lee,; Bong-Jin Lee, Structural and Biochemical Properties of Novel SelfCleaving Ribozymes. Molecules 2017, 22, 678-18. 
(94) Mlýnský, V.; Banás, P.; Walter, N. G.; Sponer, J.; Otyepka, M. QM/MM Studies of Hairpin Ribozyme Self-Cleavage Suggest the Feasibility of Multiple Competing Reaction Mechanisms. J. Phys. Chem. B 2011, 115, 13911-13924.

(95) Chval, Z.; Chvalová, D.; Leclerc, F. Modeling the RNA 2'OH Activation: Possible Roles of Metal Ion and Nucleobase as Catalysts in Self-Cleaving Ribozymes. J. Phys. Chem. B 2011, 115, 10943-10956.

(96) Diener, T. O. Potato Spindle Tuber "Virus". IV. A Replicating, Low Molecular Weight RNA. Virology 1971, $\underline{45}, 411-428$.

(97) Penedo, J. C.; Wilson, T. J.; Jayasena, S. D.; Khvorova, A.; Lilley, D. M. J. Folding of the Natural Hammerhead Ribozyme is Enhanced by Interaction of Auxiliary Elements (Chantilly, VA, U. S.). RNA 2004, 10, 880-888.

(98) Hammann, C.; Norman, D. G.; Lilley, D. Dissection of the Ion-Induced Folding of the Hammerhead Ribozyme Using F-19 NMR. Proc. Natl. Acad. Sci. U. S. A. 2001, $\underline{98}$, $5503-5508$.

(99) Scott, W. G.; Murray, J. B.; Arnold, J. R.; Stoddard, B. L.; Klug, A. Capturing the Structure of a Catalytic RNA Intermediate: the Hammerhead Ribozyme. Science 1996, 274, 2065-2069.

(100) Wang, S.; Karbstein, K.; Peracchi, A.; Beigelman, L.; Herschlag, D. Identification of the Hammerhead Ribozyme Metal Ion Binding Site Responsible for Rescue of the Deleterious Effect of a Cleavage Site Phosphorothioate. Biochemistry 1999, 38, 1436314378.

(101) de la Peña, M.; Gago, S.; Flores, R. Peripheral Regions of Natural Hammerhead Ribozymes Greatly Increase Their Self-Cleavage Activity. EMBO J. 2003, 22, 55615570. 
(102) Khvorova, A.; Lescoute, A.; Westhof, E.; Jayasena, S. D. Sequence Elements (Chantilly, VA, U. S.) Outside the Hammerhead Ribozyme Catalytic Core Enable Intracellular Activity. Nat. Struct. Biol. 2003, 10, 708-712.

(103) Canny, M. D.; Jucker, F. M.; Kellogg, E.; Khvorova, A.; Jayasena, S. D.; Pardi, A. Fast Cleavage Kinetics of a Natural Hammerhead Ribozyme. J. Am. Chem. Soc. 2004, 126, 10848-10849.

(104) Dahm, S. C.; Derrick, W. B.; Uhlenbeck, O. C. Evidence for the Role of Solvated Metal Hydroxide in the Hammerhead Cleavage Mechanism. Biochemistry 1993, $\underline{32}$, $13040-13045$.

(105) Lott, W. B.; Pontius, B. W.; von Hippel, P. H. A Two-Metal Ion Mechanism Operates in the Hammerhead Ribozyme-Mediated Cleavage of an RNA Substrate. Proc. Natl. Acad. Sci. U. S. A. 1998, 95, 542-547.

(106) Fedor, M. J.; Williamson, J. R. The Catalytic Diversity of RNAs. Nature Reviews



(107) Pley, H. W.; Flaherty, K. M.; McKay, D. B. Three-Dimensional Structure of a Hammerhead Ribozyme. Nature 1994, 372, 68-74.

(108) Chi, Y.-I.; Martick, M.; Lares, M.; Kim, R.; Scott, W. G.; Kim, S.-H. Capturing Hammerhead Ribozyme Structures in Action by Modulating General Base Catalysis. PLoS Biol. 2008, 6, 2060-2068.

(109) Buzayan, J. M.; Hampel, A.; Bruening, G. Nucleotide Sequence and Newly Formed Phosphodiester Bond of Spontaneously Ligated Satellite Tobacco Ringspot Virus RNA. Nucleic Acids Res. 1986, 14, 9729-9743.

(110) Buzayan, J. M.; Feldstein, P. A.; Bruening, G.; Eckstein, F. RNA Mediated Formation 
of a Phosphorothioate Diester Bond. Biochem. Biophys. Res. Commun. 1988, 156, 340-347.

(111) van Tol, H.; Buzayan, J. M.; Feldstein, P. A.; Eckstein, F.; Bruening, G. Two Autolytic Processing Reactions of a Satellite RNA Proceed with Inversion of Configuration. Nucleic Acids Res. 1990, 18, 1971-1975.

(112) Klostermeier, D.; Millar, D. P. Tertiary Structure Stability of the Hairpin Ribozyme in Its Natural and Minimal Forms: Different Energetic Contributions from a Ribose Zipper Motif. Biochemistry 2001, 스, 11211-11218.

(113) Ryder, S. P.; Strobel, S. A. Comparative Analysis of Hairpin Ribozyme Structures and Interference Data. Nucleic Acids Res. 2002, 30, 1287-1291.

(114) Liu, S.; Bokinsky, G.; Walter, N. G.; Zhuang, X. Dissecting the Multistep Reaction Pathway of an RNA Enzyme by Single-Molecule Kinetic "Fingerprinting". Proc. Natl. Acad. Sci. U. S. A. 2007, 104, 12634-12639.

(115) Ryder, S. P.; Oyelere, A. K.; Padilla, J. L.; Klostermeier, D.; Millar, D. P.; Strobel, S. A. Investigation of Adenosine Base Ionization in the Hairpin Ribozyme by Nucleotide Analog Interference Mapping. RNA 2001, 7, 1454-1463.

(116) MacElrevey, C.; Salter, J. D.; Krucinska, J.; Wedekind, J. E. Structural Effects of Nucleobase Variations at Key Active Site Residue Ade38 in the Hairpin Ribozyme. RNA 2008, 14, 1600-1616.

(117) Spitale, R. C.; Volpini, R.; Heller, M. G.; Krucinska, J.; Cristalli, G.; Wedekind, J. E. Identification of an Imino Group Indispensable for Cleavage by a Small Ribozyme. J. Am. Chem. Soc. 2009, 131, 6093-6095.

(118) Spitale, R. C.; Volpini, R.; Mungillo, M. V.; Krucinska, J.; Cristalli, G.; Wedekind, J. E. Single-Atom Imino Substitutions at A9 and A10 Reveal Distinct Ef- 
fects on the Fold and Function of the Hairpin Ribozyme Catalytic Core. Biochemistry 2009, $\underline{48}, 7777-7779$.

(119) Suydam, I. T.; Levandoski, S. D.; Strobel, S. A. Catalytic Importance of a Protonated Adenosine in the Hairpin Ribozyme Active Site. Biochemistry 2010, 49, 3723-3732.

(120) Cai, Z.; Tinoco, I. Solution Structure of Loop A from the Hairpin Ribozyme from Tobacco Ringspot Virus Satellite. Biochemistry 1996, 35, 6026-6036.

(121) Fedor, M. J. Comparative Enzymology and Structural Biology of RNA Self-Cleavage. Annu. Rev. Biophys. 2009, 38, 271-299.

(122) Murchie, A. I.; Thomson, J. B.; Walter, F.; Lilley, D. M. Folding of the Hairpin Ribozyme in Its Natural Conformation Achieves Close Physical Proximity of the Loops.

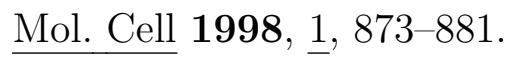

(123) Rupert, P. B.; Ferré-D’Amaré, A. R. Crystal Structure of a Hairpin RibozymeInhibitor Complex with Implications for Catalysis. Nature 2001, 410, 780-786.

(124) Ferré-D’Amaré, A. R. The Hairpin Ribozyme. Biopolymers 2004, 73, 71-78.

(125) Andersen, A. A.; Collins, R. A. Rearrangement of a Stable RNA Secondary Structure During VS Ribozyme Catalysis. Mol. Cell 2000, $\underline{5}, 469-478$.

(126) Dagenais, P.; Girard, N.; Bonneau, E.; Legault, P. Insights into RNA Structure and Dynamics from Recent NMR and X-Ray Studies of the Neurospora Varkud Satellite Ribozyme. Wiley Interdiscip. Rev.: RNA 2017, $\underline{8}$, e1421.

(127) Hoffmann, B.; Mitchell, G. T.; Gendron, P.; Major, F.; Andersen, A. A.; Collins, R. A.; Legault, P. NMR Structure of the Active Conformation of the Varkud Satellite Ribozyme Cleavage Site. Proc. Natl. Acad. Sci. U. S. A. 2003, 100, 7003-7008. 
(128) Campbell, D. O.; Legault, P. Nuclear Magnetic Resonance Structure of the Varkud Satellite Ribozyme Stem-Loop V RNA and Magnesium-Ion Binding from ChemicalShift Mapping. Biochemistry 2005, 44, 4157-4170.

(129) Pereira, M. J. B.; Nikolova, E. N.; Hiley, S. L.; Jaikaran, D.; Collins, R. A.; Walter, N. G. Single VS Ribozyme Molecules Reveal Dynamic and Hierarchical Folding Toward Catalysis. J. Mol. Biol. 2008, 382, 496-509.

(130) Wilson, T. J.; McLeod, A. C.; Lilley, D. M. J. A Guanine Nucleobase Important for Catalysis by the VS Ribozyme. EMBO J. 2007, 26, 2489-2500.

(131) Smith, M. D.; Mehdizadeh, R.; Olive, J. E.; Collins, R. A. The Ionic Environment Determines Ribozyme Cleavage Rate by Modulation of Nucleobase PK A. RNA 2008, 14, 1942-1949.

(132) Suydam, I. T.; Strobel, S. A. Fluorine Substituted Adenosines as Probes of Nucleobase Protonation in Functional RNAs. J. Am. Chem. Soc. 2008, 130, 13639-13648.

(133) Wilson, T. J.; Lilley, D. M. J. Do the Hairpin and VS Ribozymes Share a Common Catalytic Mechanism Based on General Acid-Base Catalysis? A Critical Assessment of Available Experimental Data. RNA 2011, 17, 213-221.

(134) Nakano, S.-i.; Cerrone, A. L.; Bevilacqua, P. C. Mechanistic Characterization of the HDV Genomic Ribozyme: Classifying the Catalytic and Structural Metal Ion Sites within a Multichannel Reaction Mechanism. Biochemistry 2003, 42, 2982-2994.

(135) Perrotta, A. T.; Been, M. D. HDV Ribozyme Activity in Monovalent Cations. Biochemistry 2006, 45, 11357-11365.

(136) Nakano, S.-i.; Bevilacqua, P. C. Mechanistic Characterization of the HDV Genomic Ribozyme: a Mutant of the C41 Motif Provides Insight into the Positioning and 
Thermodynamic Linkage of Metal Ions and Protons. Biochemistry 2007, 46, 30013012 .

(137) Veeraraghavan, N.; Ganguly, A.; Chen, J.-H.; Bevilacqua, P. C.; Hammes-Schiffer, S.; Golden, B. L. Metal Binding Motif in the Active Site of the HDV Ribozyme Binds Divalent and Monovalent Ions. Biochemistry 2011, 50, 2672-2682.

(138) Thaplyal, P.; Ganguly, A.; Golden, B. L.; Hammes-Schiffer, S.; Bevilacqua, P. C. Thio Effects and an Unconventional Metal Ion Rescue in the Genomic Hepatitis Delta Virus Ribozyme. Biochemistry 2013, 52, 6499-6514.

(139) Chen, J.; Ganguly, A.; Miswan, Z.; Hammes-Schiffer, S.; Bevilacqua, P. C.; Golden, B. L. Identification of the Catalytic Mg ion in the hepatitis delta virus ri-

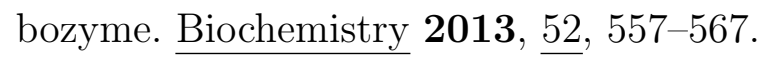

(140) Xin, Y.; Hamelberg, D. Deciphering the Role of Glucosamine-6-Phosphate in the Riboswitch Action of glmS Ribozyme. RNA 2010, 16, 2455-2463.

(141) Ferré-D'Amaré, A. R. Use of a Coenzyme by the glmS Ribozyme-Riboswitch Suggests Primordial Expansion of RNA Chemistry by Small Molecules. Phil. Trans. R. Soc. B 2011, 366, 2942-2948.

(142) Klawuhn, K.; Jansen, J. A.; Souchek, J.; Soukup, G. A.; Soukup, J. K. Analysis of Metal Ion Dependence in glmS Ribozyme Self-Cleavage and Coenzyme Binding. Chembiochem 2010, 11, 2567-2571.

(143) Cech, T. R. The Ribosome is a Ribozyme. 2000, 289, 878-879.

(144) Steitz, T. A.; Moore, P. B. RNA, the First Macromolecular Catalyst: the Ribosome is a Ribozyme. Trends Biochem. Sci. 2003, 28, 411-418.

(145) Yonath, A. Large Facilities and the Evolving Ribosome, the Cellular Machine for 
Genetic-Code Translation. J. R. Soc., Interface, Interface / the Royal Society 2009, $\underline{6}$ Suppl 5, S575-85.

(146) Kawamura, K. Behaviour of RNA under Hydrothermal Conditions and the Origins of Life. Int. J. Astrobiol. 2005, 3, 301-309.

(147) Hernández, A. R.; Piccirilli, J. A. Chemical Origins of Life: Prebiotic RNA Unstuck. Nat. Chem. 2013, 5, 360-362.

(148) Quéméneur, M.; Erauso, G.; Frouin, E.; Zeghal, E.; Vandecasteele, C.; Ollivier, B.; Tamburini, C.; Garel, M.; Ménez, B.; Postec, A. Hydrostatic Pressure Helps to Cultivate an Original Anaerobic Bacterium from the Atlantis Massif Subseafloor (IODP Expedition 357): Petrocella Atlantisensis Gen. Nov. Sp. Nov. Front. Microbiol. 2019, 10, 1497.

(149) Takami, H.; Inoue, A.; Fuji, F.; Horikoshi, K. Microbial Flora in the Deepest Sea Mud of the Mariana Trench. FEMS Microbiol. Lett. 2006, 152, 279-285.

(150) Mota, M. J.; Lopes, R. P.; Delgadillo, I.; Saraiva, J. A. Microorganisms under High Pressure Adaptation, growth and biotechnological potential. Biotechnol. Adv. 2013, 31, $1426-1434$.

(151) Gayán, E.; Govers, S. K.; Aertsen, A. Impact of High Hydrostatic Pressure on Bacterial Proteostasis. Biophys. Chem. 2017, 231, 3-9.

(152) Rousselet, A.; Euteneuer, U.; Bordes, N.; Ruiz, T.; Hui Bon Hua, G.; Bornens, M. Structural and Functional Effects of Hydrostatic Pressure on Centrosomes from Ver-

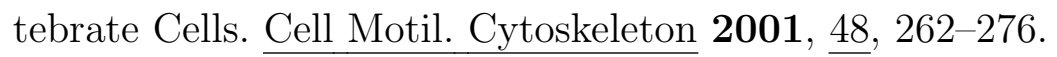

(153) Siliakus, M. F.; van der Oost, J.; Kengen, S. W. M. Adaptations of Archaeal and Bacterial Membranes to Variations in Temperature, PH and Pressure. Extremophiles 2017, 21, 651-670. 
(154) Hei, D. J.; Clark, D. S. Pressure Stabilization of Proteins from Extreme Thermophiles. Appl. Environ. Microbiol. 1994, 60, 932-939.

(155) Schmidt, A.; Hall, M. N.; Koller, A. Two FK506 Resistance-Conferring Genes in Saccharomyces Cerevisiae, TAT1 and TAT2, Encode Amino Acid Permeases Mediating Tyrosine and Tryptophan Uptake. Mol. Cell. Biol. 1994, 14, 6597-6606.

(156) Nakasone, K.; Ikegami, A.; Kato, C.; Usami, R.; Horikoshi, K. Analysis of CisElements upstream of the Pressure-Regulated Operon in the Deep-Sea Barophilic Bacterium Shewanella Violacea Strain DSS12. FEMS Microbiol. Lett. 176, 351-356.

(157) Van Eldik, R.; Asano, T.; Le Noble, W. J. Activation and Reaction Volumes in Solution. 2. Chem. Rev. (Washington, DC, U. S.) 1989, 89, 549-688.

(158) DeLong, E. F.; Yayanos, A. A. Adaptation of the Membrane Lipids of a Deep-Sea Bacterium to Changes in Hydrostatic Pressure. Science 1985, 228, 1101-1103.

(159) Qureshi, M. H.; Kato, C.; K, H. Purification of Two Pressure-Regulated C-Type Cytochromes from a Deep-Sea Barophilic Bacterium, Shewanella Sp. Strain DB-172F. FEMS Microbiol. Lett. 1998, 161, 301-309.

(160) Swezey, R. R.; Somero, G. N. Polymerization Thermodynamics and Structural Stabilities of Skeletal Muscle Actins from Vertebrates Adapted to Different Temperatures and Hydrostatic Pressures. Biochemistry 1982, 21, 4496-4503.

(161) Morild, E. The Theory of Pressure Effects on Enzymes. Adv. Protein Chem. 1981, $\underline{34}, 93-166$.

(162) Heremans, K. High Pressure Effects on Proteins and Other Biomolecules. Annu. Rev. Biophys. Bioeng. 1982, 11, 1-21.

(163) Weber, G.; Drickamer, H. G. The Effect of High Pressure upon Proteins and Other Biomolecules. Q. Rev. Biophys. 1983, 16, 89-112. 
(164) Balny, C.; Masson, P. Effects of High Pressure on Proteins. Food Rev. Int. 1993, 9, $611-628$.

(165) Mozhaev, V. V.; Heremans, K.; Frank, J.; Masson, P.; Balny, C. High Pressure Effects on Protein Structure and Function. Proteins: Struct., Funct., Bioinf. 1996, 24, 81-91.

(166) Hervé, G. In Cell Mechanochemistry. Biological Systems and Factors Inducing Mechanical Stress, Such as Light, Pressure and Gravity; Monici, M., van Loon, J. J. W. A., Eds.; Transworld Research Network, 2010; Chapter 13. High Pressure in Biology, pp 267-283.

(167) Cinar, H.; Fetahaj, Z.; Cinar, S.; Vernon, R. M.; Chan, H. S.; Winter, R. H. A. Temperature, Hydrostatic Pressure, and Osmolyte Effects on Liquid-Liquid Phase Separation in Protein Condensates: Physical Chemistry and Biological Implications. Chem. - Eur. J., Germany) 2019, 94, 570.

(168) Balny, C.; Masson, P.; Heremans, K. High Pressure Effects on Biological Macromolecules: from Structural Changes to Alteration of Cellular Processes. Biochim. Biophys. Acta 2002, 1595, 3-10.

(169) Silva, J. L.; Oliveira, A. C.; Vieira, T. C. R. G.; de Oliveira, G. a. P.; Suarez, M. C.; Foguel, D. High-Pressure Chemical Biology and Biotechnology. Chem. Rev. (Washington, DC, U. S.) 2014, 114, 7239-7267.

(170) Roche, J.; Dellarole, M.; Caro, J. A.; Norberto, D. R.; Garcia, A. E.; GarciaMoreno, B.; Roumestand, C.; Royer, C. A. Effect of Internal Cavities on Folding Rates and Routes Revealed by Real-Time Pressure-Jump NMR Spectroscopy. J. Am. Chem. Soc. 2013, 135, 14610-14618.

(171) de Oliveira, G. A. P.; Silva, J. L. A Hypothesis to Reconcile the Physical and Chemical Unfolding of Proteins. Proc. Natl. Acad. Sci. U. S. A. 2015, 112, E2775-84. 
(172) Krobath, H.; Chen, T.; Chan, H. S. Volumetric Physics of Polypeptide Coil-Helix Transitions. Biochemistry 2016, 55, 6269-6281.

(173) Wang, S.; Tate, M. W.; Gruner, S. M. Protein Crowding Impedes Pressure-Induced Unfolding of Staphylococcal Nuclease. Biochim. Biophys. Acta (BBA) - General Subjects 2012, 1820, 957-961.

(174) Nakano, S.-i.; Miyoshi, D.; Sugimoto, N. Effects of Molecular Crowding on the Structures, Interactions, and Functions of Nucleic Acids. Chem. Rev. (Washington, DC, U. S.) 2013, 114, 2733-2758.

(175) Meersman, F.; Smeller, L.; Heremans, K. Protein Stability and Dynamics in the Pressure-Temperature Plane. Biochim. Biophys. Acta 2006, 1764, 346-354.

(176) Meersman, F.; Daniel, I.; Bartlett, D. H.; Winter, R.; Hazael, R.; McMillan, P. F. High-Pressure Biochemistry and Biophysics. Rev. Mineral. Geochem. 2013, 75, 607648.

(177) Bassez, M.-P. Is High-Pressure Water the Cradle of Life? J. Phys.: Condens. Matter 2003, 15, L353-L361.

(178) Corliss JB, H. S., Baross JA Submarine Hydrothermal Systems: a Probable Site for the Origin of Life. Oceanol. Acta 1981, 4, 59-69.

(179) Wächtershäuser, G. Before Enzymes and Templates: Theory of Surface Metabolism. Microbiol. Rev. 1988, 52, 452-484.

(180) Hui Bon Hoa, G.; Hamel, G.; Else, A.; Weill, G.; Hervé, G. A Reactor Permitting Injection and Sampling for Steady State Studies of Enzymatic Reactions at High Pressure: Tests with Aspartate Transcarbamylase. Anal. Biochem. 1990, 187, 258261. 
(181) Balny, C.; Saldana, J. L.; Dahan, N. High-Pressure Stopped-Flow Fluorometry at Subzero Temperatures: Application to Kinetics of the Binding of NADH to Liver Alcohol Dehydrogenase. Anal. Biochem. 1987, 163, 309-315.

(182) Kawamura, K. Hydrothermal Microflow Technology as a Research Tool for Origin-ofLife Studies in Extreme Earth Environments. Life 2017, 7, 2-19.

(183) Fourme, R.; Girard, E.; Kahn, R.; Dhaussy, A.-C.; Ascone, I. Advances in HighPressure Biophysics: Status and Prospects of Macromolecular Crystallography. Annu.

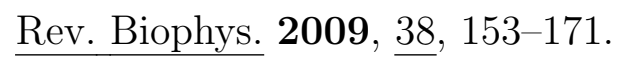

(184) Asano, T.; Le Noble, W. J. Activation and Reaction Volumes in Solution. Chem. Rev. (Washington, DC, U. S.) 1978, 78, 407-489.

(185) Drljaca, A.; Hubbard, C. D.; Van Eldik, R.; Asano, T.; Basilevsky, M. V.; Le Noble, W. J. Activation and Reaction Volumes in Solution. 3. Chem. Rev. (Washington, $\underline{\text { DC, U. S.) }}$ 1998, $\underline{98}, 2167-2290$.

(186) Gross, M.; Jaenicke, R. Proteins under Pressure. the Influence of High Hydrostatic Pressure on Structure, Function and Assembly of Proteins and Protein Complexes. Eur. J. Biochem. 1994, 221, 617-630.

(187) Royer, C. A. Revisiting Volume Changes in Pressure-Induced Protein Unfolding. Biochim. Biophys. Acta 2002, 1595, 201-209.

(188) Chilukuri, L. N.; Bartlett, D. H.; Fortes, P. A. G. Comparison of High Pressure-Induced Dissociation of Single-Stranded DNA-Binding Protein (SSB) from High Pressure-Sensitive and High Pressure-Adapted Marine Shewanella Species. Extremophiles 2002, $\underline{6}, 377-383$.

(189) Parsegian, V. A.; Rand, R. P.; Rau, D. C. [3] Macromolecules and Water: Probing with Osmotic Stress. Methods Enzymol. 1995, 259, 43-94. 
(190) Parsegian, V. A.; Rand, R. P.; Fuller, N. L.; Rau, D. C. [29] Osmotic Stress for the Direct Measurement of Intermolecular Forces. Methods Enzymol. 1986, 127, 400-416.

(191) Rau, D. C.; Lee, B.; Parsegian, V. A. Measurement of the Repulsive Force Between Polyelectrolyte Molecules in Ionic Solution: Hydration Forces Between Parallel DNA Double Helices. Proc. Natl. Acad. Sci. U. S. A. 1984, 81, 2621-2625.

(192) Macgregor, R. B. Effect of Hydrostatic Pressure on Nucleic Acids. Biopolymers 1998, $\underline{48}, 253-263$.

(193) Tang, G. Q.; Tanaka, N.; Kunugi, S. In vitro Increases in Plasmid DNA Supercoiling by Hydrostatic Pressure. Biochim. Biophys. Acta 1998, 1443, 364-368.

(194) Dubins, D. N.; Lee, A.; Macgregor, R. B.; Chalikian, T. V. On the Stability of Double Stranded Nucleic Acids. J. Am. Chem. Soc. 2001, 123, 9254-9259.

(195) Macgregor, R. B.; Chen, M. Y. Delta V0 of the Na(+)-Induced B-Z Transition of Poly $[\mathrm{D}(\mathrm{G}-\mathrm{C})]$ is Positive. Biopolymers 1990, 29, 1069-1076.

(196) Barciszewski, J.; Jurczak, J.; Porowski, S.; Specht, T.; Erdmann, V. A. The Role of Water Structure in Conformational Changes of Nucleic Acids in Ambient and HighPressure Conditions. Eur. J. Biochem. 1999, 260, 293-307.

(197) Giel-Pietraszuk, M.; Barciszewski, J. A Nature of Conformational Changes of Yeast tRNA(Phe). High Hydrostatic Pressure Effects. Int. J. Biol. Macromol. 2005, 37, $109-114$.

(198) Jaenicke, R. Enzymes under Extremes of Physical Conditions. Annu. Rev. Biophys. Bioeng. 1981, 10, 1-67.

(199) Gross, M.; Lehle, K.; Jaenicke, R.; Nierhaus, K. H. Pressure-Induced Dissociation of Ribosomes and Elongation Cycle Intermediates. Stabilizing Conditions and Identification of the Most Sensitive Functional State. Eur. J. Biochem. 1993, 218, 463-468. 
(200) Niven, G. W.; Miles, C. A.; Mackey, B. M. The Effects of Hydrostatic Pressure on Ribosome Conformation in Escherichia Coli: and in vivo Study Using Differential Scanning Calorimetry. Microbiology 1999, 145 ( Pt 2), 419-425.

(201) Schulz, E.; Jaenicke, R.; Knoche, W. Pressure-Jump Relaxation Studies of the Association-Dissociation Reaction of E. Coli Ribosomes. Biophys. Chem. 1976, $\underline{4}$, 253-257.

(202) Krzyzaniak, A.; Barciszewski, J.; Sałański, P.; Jurczak, J. The Non-Enzymatic Specific Amino-Acylation of Transfer RNA at High Pressure. Int. J. Biol. Macromol. 1994, $\underline{16}, 153-158$.

(203) Krzyzaniak, A.; Sałański, P.; Twardowski, T.; Jurczak, J.; Barciszewski, J. TRNA Aminoacylated at High Pressure is a Correct Substrate for Protein Biosynthesis. Biochem. Mol. Biol. Int. 1998, 45, 489-500.

(204) Giel-Pietraszuk, M.; Barciszewski, J. Charging of tRNA with Non-Natural Amino Acids at High Pressure. FEBS J. 2006, 273, 3014-3023.

(205) Downey, C. D.; Crisman, R. L.; Randolph, T. W.; Pardi, A. Influence of Hydrostatic Pressure and Cosolutes on RNA Tertiary Structure. J. Am. Chem. Soc. 2007, 129, 9290-9291.

(206) Schuabb, C.; Pataraia, S.; Berghaus, M.; Winter, R. Exploring the Effects of Temperature and Pressure on the Structure and Stability of a Small RNA Hairpin. Biophys. Chem. 2017, 231, 161-166.

(207) Kumar, P.; Lehmann, J.; Libchaber, A. Kinetics of Bulge Bases in Small RNAs and the Effect of Pressure on It. PLoS One 2012, $\underline{7}$, e42052.

(208) Librizzi, F.; Carrotta, R.; Peters, J.; Cupane, A. The Effects of Pressure on the Energy Landscape of Proteins. Sci. Rep. 2018, $\underline{8}, 2037$. 
(209) Kirillova, S.; Carugo, O. Hydration Sites of Unpaired RNA Bases: a Statistical Analysis of the PDB Structures. BMC Struct. Biol. 2010, 11, 41-41.

(210) Komatsu, Y.; Kanzaki, I.; Koizumi, M.; Ohtsuka, E. Construction of New Hairpin Ribozymes with Replaced Domains. Nucleic Acids Symp. Ser. 1995, 34, 223-224.

(211) Feldstein, P. A.; Bruening, G. Catalytically Active Geometry in the Reversible Circularization of 'mini-Monomer' RNAs Derived from the Complementary Strand of Tobacco Ringspot Virus Satellite RNA. Nucleic Acids Res. 1993, 21, 1991-1998.

(212) Tobé, S.; Heams, T.; Vergne, J.; Hervé, G.; Maurel, M.-C. The Catalytic Mechanism of Hairpin Ribozyme Studied by Hydrostatic Pressure. Nucleic Acids Res. 2005, 33, 2557-2564.

(213) Salter, J.; Krucinska, J.; Alam, S.; Grum-Tokars, V.; Wedekind, J. E. Water in the Active Site of an All-RNA Hairpin Ribozyme and Effects of Gua8 Base Variants on the Geometry of Phosphoryl Transfer. Biochemistry 2006, 45, 686-700.

(214) Kumar, N.; Marx, D. Mechanistic Role of Nucleobases in Self-Cleavage Catalysis of Hairpin Ribozyme at Ambient Versus High-Pressure Conditions. Phys. Chem. Chem. Phys. 2018, 20, 20886-20898.

(215) Kumar, N.; Marx, D. How Do Ribozymes Accommodate Additional Water Molecules upon Hydrostatic Compression Deep into the Kilobar Pressure Regime? Biophys. Chem. 2019, 252, 106192.

(216) Paudel, B. P.; Rueda, D. Molecular Crowding Accelerates Ribozyme Docking and Catalysis. J. Am. Chem. Soc. 2014, 136, 16700-16703.

(217) Daher, M.; Widom, J. R.; Tay, W.; Walter, N. G. Soft Interactions with Model Crowders and Non-Canonical Interactions with Cellular Proteins Stabilize RNA Folding. J. Mol. Biol. 2018, 430, 509-523. 
(218) Meli, M.; Vergne, J.; Décout, J.-L.; Maurel, M.-C. Adenine-Aptamer Complexes: a Bipartite RNA Site that Binds the Adenine Nucleic Base. J. Biol. Chem. 2002, 277, $2104-2111$.

(219) Kuzmin, Y. I.; Da Costa, C. P.; Cottrell, J. W.; Fedor, M. J. Role of an Active Site Adenine in Hairpin Ribozyme Catalysis. J. Mol. Biol. 2005, 349, 989-1010.

(220) Ztouti, M.; Kaddour, H.; Miralles, F.; Simian, C.; Vergne, J.; Hervé, G.; Maurel, M.C. Adenine, a Hairpin Ribozyme Cofactor-High-Pressure and Competition Studies. FEBS J. 2009, 276, 2574-2588.

(221) Giel-Pietraszuk, M.; Fedoruk-Wyszomirska, A.; Barciszewski, J. Effect of High Hydrostatic Pressure on Hydration and Activity of Ribozymes. Mol. Biol. Rep. 2010, $\underline{37}, 3713-3719$.

(222) Kaddour, H.; Vergne, J.; Hervé, G.; Maurel, M.-C. High-Pressure Analysis of a Hammerhead Ribozyme from Chrysanthemum Chlorotic Mottle Viroid Reveals Two Different Populations of Self-Cleaving Molecule. FEBS J. 2011, 278, 3739-3747.

(223) Fedoruk-Wyszomirska, A.; Wyszko, E.; Giel-Pietraszuk, M.; Barciszewska, M. Z.; Barciszewski, J. High Hydrostatic Pressure Approach Proves RNA Catalytic Activity Without Magnesium. Int. J. Biol. Macromol. 2007, 41, 30-35.

(224) O’Rourke, S. M.; Estell, W.; Scott, W. G. Minimal Hammerhead Ribozymes with Uncompromised Catalytic Activity. J. Mol. Biol. 2015, 427, 2340-2347.

(225) El-Murr, N.; Maurel, M.-C.; Rihova, M.; Vergne, J.; Hervé, G.; Kato, M.; Kawamura, K. Behavior of a Hammerhead Ribozyme in Aqueous Solution at Medium to High Temperatures. Naturwissenschaften 2012, 99, 731-738.

(226) Desai, R.; Kilburn, D.; Lee, H.-T.; Woodson, S. A. Increased Ribozyme Activity in Crowded Solutions. J. Biol. Chem. 2014, 289, 2972-2977. 
(227) Paudel, B. P.; Fiorini, E.; Börner, R.; Sigel, R. K. O.; Rueda, D. S. Optimal Molecular Crowding Accelerates Group II Intron Folding and Maximizes Catalysis. Proc. Natl. Acad. Sci. U. S. A. 2018, 115, 11917-11922.

(228) Nashimoto, M. Correct Folding of a Ribozyme Induced by Nonspecific Macromolecules. Eur. J. Biochem. 2000, 267, 2738-2745.

(229) Lau, M. W. L.; Ferré-D'Amaré, A. R. An in vitro Evolved glmS Ribozyme Has the Wild-Type Fold but Loses Coenzyme Dependence. Nat. Chem. Biol. 2013, 9, 805-810.

(230) White, H. I. In The Pyridine Nucleotide Coenzymes; Everse J., Y. K. E., Anderson B., Ed.; Academic Press: New York, NY, USA, 1982; Chapter 1. Evolution of Coenzymes and the Origin of Pyridine Nucleotides.

(231) Illangasekare, M.; Yarus, M. A Tiny RNA that Catalyzes both Aminoacyl-RNA and Peptidyl-RNA Synthesis. RNA 1999, $\underline{5}, 1482-1489$.

(232) Lustig, B.; Baharand, I.; Jernigan, R. L. RNA Bulge Entropies in the Unbound State Correlate with Peptide Binding Strengths for HIV-1 and BIV TAR RNA Because of Improved Conformational Access. Nucleic Acids Res. 1998, 26, 5212-5217.

(233) Buck, J.; Li, Y.-L.; Richter, C.; Vergne, J.; Maurel, M.-C.; Schwalbe, H. NMR Spectroscopic Characterization of the Adenine-Dependent Hairpin Ribozyme. Chembiochem 2009, 10, 2100-2110.

(234) Leclerc, F.; Zaccai, G.; Vergne, J.; Rihova, M.; Martel, A.; Maurel, M.-C. SelfAssembly Controls Self-Cleavage of HHR from ASBVd (-): a Combined SANS and Modeling Study. Sci. Rep. 2016, $\underline{6}, 30287$.

(235) Maurel, M.-C.; Leclerc, F. From Foundation Stones to Life: Concepts and Results. Elements (Chantilly, VA, U. S.) 2016, 12, 407-412. 
Graphical TOC Entry

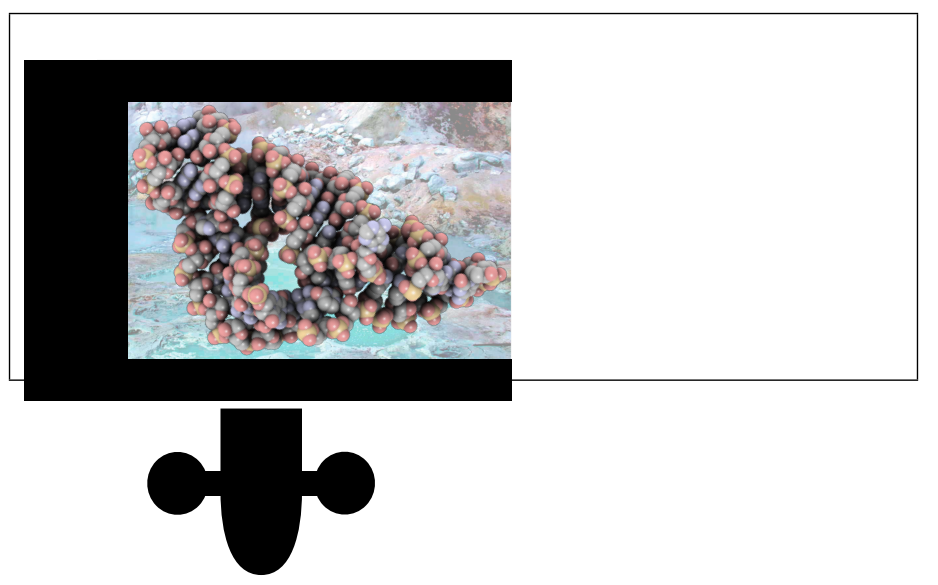

